\title{
On a Class of Nonlinear Transformations and Their Applications to the Evaluation of Infinite Series*
}

\author{
H. L. Gray ${ }^{1}$ and W. D. Clark ${ }^{2}$
}

(March 12, 1969)

\begin{abstract}
In this paper the problem of increasing the rate of convergence of infinite sequences and series is considered by means of a class of nonlinear transformations. The transformations employed are the discrete analogue of the so called $G$-transformations and the theory surrounding them is investigated in some detail. The theoretical results are demonstrated by numerous examples.
\end{abstract}

Key words: Aitken transformations; $G$-transformations; nonlinear transformations; rapidity of convergence.

\section{Introduction}

In several recent papers $[5,6,7,8]^{3}$ H. L. Gray, T. A. Atchison, and others have considered a class of nonlinear transformations, referred to as $G$-transformations, for the purpose of evaluating improper integrals. The complete motivation for these transformations is given in [7] although the underlying concept which suggested this motivation is contained in an earlier paper [11] by S. Lubkin. However the setting in [7] affords a certain degree of generality not obtainable in [11] and thus suggests a general class of nonlinear transformation which might be of use in the problem of [11], i.e., the problem of increasing the rate of convergence of an infinite series to its limit.

To be more specific. In [7] the $G$-transformation, or the class of transformations referred to as $G$-transformations, is defined as follows:

Let $f$ be a continuous function on $[a, \infty)$ and let

$$
F(t)=\int_{a}^{t} f(x) d x \rightarrow S \neq \mp \infty \text { as } t \rightarrow \infty
$$

Moreover let

$$
R(t, g(t))=\frac{f(t)}{f(g(t)) g^{\prime}(t)},
$$

where $g(t) \rightarrow \infty$ as $t \rightarrow \infty$. Then the $G$-transformation is defined by

$$
G[F ; g(t), t]=\frac{F(t)-R(t, g(t)) F(g(t))}{1-R(t, g(t))} .
$$

From the motivation which produced (1.3) $G[F: g(t), t]$ was expected to be of some value in the direct evaluation of improper integrals. As has been demonstrated in $[5,6,7,8]$ this turns out to be the case.

\footnotetext{
*An invited paper.

1 Texas Technological College, Lubbock, Texas 79406.

${ }^{2}$ Stephen F. Austin State College, Nacogdoches, Texas 75961.

${ }^{3}$ Figures in brackets indicate the literature references at the end of this paper.
} 
In this paper a discrete version of (1.3) is considered for the purpose of increasing the rate of convergence of an infinite series. It is shown that the $e_{1}$ (Shanks) or $T$ (Lubkin) transformation arises in a natural way from this class of transformations. Moreover close consideration is given to the ratio $R[n, g(n)]$ as a guide for selecting the appropriate transformation for a given series.

The important special cases in which $\lim _{n \rightarrow \infty} R[n, g(n)]=0,1$ are studied in some detail. Several examples are included.

Before formally defining the class of transformations which is the subject of this paper we give the following definitions.

Definition 1.1: Let $\mathrm{A}(\mathrm{n})$ and $\mathrm{B}(\mathrm{n})$ be sequences of real numbers such that $\lim _{n \rightarrow \infty} \mathrm{A}(\mathrm{n})=\mathrm{A}$ and $\lim _{n \rightarrow \infty} \mathrm{B}(\mathrm{n})=\mathrm{B}$ and suppose

$$
\lim _{n \rightarrow \infty}\left|\frac{\mathrm{A}(\mathrm{n})-\mathrm{A}}{\mathrm{B}(\mathrm{n})-\mathrm{B}}\right|=\mathrm{L} \neq \infty \text {. }
$$

Then we say $A(n)$ converges more rapidly than $B(n)$ if $L=0$ and at the same rate as $B(n)$ if $L \neq 0$.

DEFINITION 1.2: If

$$
|\mathrm{A}(\mathrm{n})-\mathrm{A}|<|\mathrm{B}(\mathrm{n})-\mathrm{B}|
$$

for all $\mathrm{n} \epsilon(\mathrm{a}, \mathrm{b})$ then we say that $\mathrm{A}(\mathrm{n})$ converges uniformly better than $\mathrm{B}(\mathrm{n})$ on $(\mathrm{a}, \mathrm{b})$.

The following simple theorem connects these two definitions.

THEOREM 1.1: If $\mathrm{A}(\mathrm{n})$ converges more rapidly than $\mathrm{B}(\mathrm{n})$, then there exists an $\mathrm{N}$ such that $\mathrm{A}(\mathrm{n})$ converges uniformly better than $\mathrm{B}(\mathrm{n})$ on $(\mathrm{N}, \infty)$.

Proof: The proof is trivial and can be found in [7].

DEFINITION 1.3: We say a transformation $\mathrm{T}$ defined on $\mathrm{A}(\mathrm{n})$ is exact if there exists an $\mathrm{N}<\infty$ such that $\mathrm{T}[\mathrm{A}(\mathrm{n})]=\mathrm{L}$ if $\mathrm{n}>\mathrm{N}$, where $\lim _{n \rightarrow \infty} \mathrm{A}(\mathrm{n})=\mathrm{L}$.

\section{The $T$ Transformation}

DEFINITION 2.1: Let $\mathrm{g}$ be a positive, integer valued function defined on the nonnegative integers such that $\lim _{\mathrm{n} \rightarrow \infty} \mathrm{g}(\mathrm{n})=\infty$.

Also let

$$
\mathrm{S}(\mathrm{n})=\sum_{\mathrm{k}=1}^{\mathrm{n}} \mathrm{a}(\mathrm{k}) \rightarrow \mathrm{S} \neq \mp \infty \text { as } \mathrm{n} \rightarrow \infty
$$

and

$$
\mathrm{R}[\mathrm{n}, \mathrm{g}(\mathrm{n})]=\frac{\mathrm{a}(\mathrm{n})}{\mathrm{a}[\mathrm{g}(\mathrm{n})][\mathrm{g}(\mathrm{n}+1)-\mathrm{g}(\mathrm{n})]}=\frac{\mathrm{a}(\mathrm{n})}{\mathrm{a}[\mathrm{g}(\mathrm{n})] \Delta \mathrm{g}(\mathrm{n})} .
$$

Then we define the $\mathrm{T}$ transformation by

$$
\mathrm{T}[\mathrm{S}(\mathrm{n}) ; \mathrm{g}(\mathrm{n})]=\frac{\mathrm{S}(\mathrm{n})-\mathrm{R}[\mathrm{n}, \mathrm{g}(\mathrm{n})] \mathrm{S}[\mathrm{g}(\mathrm{n})]}{1-\mathrm{R}[\mathrm{n}, \mathrm{g}(\mathrm{n})]}, \mathrm{R}[\mathrm{n}, \mathrm{g}(\mathrm{n})] \neq 1 .
$$

We assume that either $\mathrm{a}[\mathrm{g}(\mathrm{n})] \Delta \mathrm{g}(\mathrm{n}) \neq 0$ or if $\mathrm{a}[\mathrm{g}(\mathrm{n})] \Delta \mathrm{g}(\mathrm{n})=0$ then $\lim _{x \rightarrow n} \mathrm{R}[\mathrm{x}, \mathrm{g}(\mathrm{x})]$ exists and we define $\mathrm{R}[\mathrm{n}, \mathrm{g}(\mathrm{n})]$ to be that limit. Unless stated to the contrary we will not necessarily assume $\lim _{n \rightarrow \infty} \mathrm{R}[\mathrm{n}, \mathrm{g}(\mathrm{n})]$ exists. Throughout it will be assumed that $\mathrm{S}$ has an infinite number of nonzero terms.

THEOREM 2.1: For every function $\mathrm{g}$ for which there exists an $\mathrm{M}>0$ such that

$$
|1-\mathrm{R}[\mathrm{n}, \mathrm{g}(\mathrm{n})]| \geqslant \mathrm{M}
$$

for $\mathrm{n}$ sufficiently large, $\mathrm{T}[\mathrm{S}(\mathrm{n}) ; \mathrm{g}(\mathrm{n})] \rightarrow \mathrm{S}$ as $\mathrm{n} \rightarrow \infty$.

Proof: Since

$$
T[S(n) ; g(n)]-S[g(n)]=\frac{S(n)-S[g(n)]}{1-R[n, g(n)]} \rightarrow 0
$$


as $n \rightarrow \infty$, then the theorem follows.

COROLlaRY 2.1: If $\lim _{\mathrm{n} \rightarrow \infty} \mathrm{R}[\mathrm{n}, \mathrm{g}(\mathrm{n})]$ exists and is different from 1 , then $\mathrm{T}[\mathrm{S}(\mathrm{n}) ; \mathrm{g}(\mathrm{n})] \rightarrow \mathrm{S}$ as $\mathrm{n} \rightarrow \infty$.

THEOREM 2.2: If $\lim _{\mathrm{n} \rightarrow \infty} \mathrm{R}[\mathrm{n}, \mathrm{g}(\mathrm{n})]=\mathrm{L}(\mathrm{g}) \neq 1, \mathrm{~L}(\mathrm{~g})$ finite, and

$$
\frac{\mathrm{S}-\mathrm{S}(\mathrm{n})}{\mathrm{S}-\mathrm{S}[\mathrm{g}(\mathrm{n})]} \rightarrow \mathrm{L}(\mathrm{g})
$$

then $\mathrm{T}[\mathrm{S}(\mathrm{n}) ; \mathrm{g}(\mathrm{n})]$ converges more rapidly than $\mathrm{S}[\mathrm{g}(\mathrm{n})]$.

Further, if $\mathrm{L}(\mathrm{g}) \neq 1$ or 0 , then $\mathrm{T}[\mathrm{S}(\mathrm{n})]$ converges more rapidly than either $\mathrm{S}[\mathrm{g}(\mathrm{n})]$ or $\mathrm{S}(\mathrm{n})$ if and only if (2.6) holds.

Proof: Since

$$
\frac{S-T[S(n) ; g(n)]}{S-S(n)}=\frac{1}{1-R[n, g(n)]}\left\{1-R[n, g(n)] \frac{S-S[g(n)]}{S-S(n)}\right\}
$$

and

$$
\frac{S-T[S(n) ; g(n)]}{S-S[g(n)]}=\frac{1}{1-R[n, g(n)]}\left\{\frac{S-S(n)}{S-S[g(n)]}-R[n, g(n)]\right\}
$$

then the result follows.

COROLLARY 2.2: Under the conditions of Theorem 2.2, there exists an $\mathrm{N}$ such that $\mathrm{T}[\mathrm{S}(\mathrm{n})$; $\mathrm{g}(\mathrm{n})]$ converges uniformly better than $\mathrm{S}(\mathrm{n})$ or $\mathrm{S}[\mathrm{g}(\mathrm{n})]$ on $(\mathrm{N}, \infty)$.

Proof: The result follows from Theorem 1.1.

THEOREM 2.3: T[S(n); g(n)] converges uniformly better than $\mathrm{S}(\mathrm{n})$ on $(\mathrm{a}, \mathrm{b})$ if and only if

$$
-2<\frac{\mathrm{R}[\mathrm{n}, \mathrm{g}(\mathrm{n})]}{1-\mathrm{R}[\mathrm{n}, \mathrm{g}(\mathrm{n})]} \frac{\mathrm{S}[\mathrm{g}(\mathrm{n})]-\mathrm{S}(\mathrm{n})}{\mathrm{E}(\mathrm{n})}<0
$$

on $(\mathrm{a}, \mathrm{b})$, where $\mathrm{E}(\mathrm{n})=\sum_{\mathrm{k}=\mathrm{n}+1}^{\infty} \mathrm{a}(\mathrm{k})=\mathrm{S}-\mathrm{S}(\mathrm{n})$.

Consider now the following examples.

EXAMPLE 2.1: Let

$$
S(m)=\sum_{k=0}^{m} 2^{-k} \rightarrow 2 \text { as } m \rightarrow \infty
$$

and let $g(m)=m^{2}$. Then

$$
\begin{gathered}
a(m)=2^{-m}, \\
a[g(m)]=2^{-m^{2}}, \text { and } \\
R[m ; g(m)]=\frac{2^{-m}}{2^{-m^{2}}\left[(m+1)^{2}-m^{2}\right]}=\frac{2^{m(m-1)}}{2 m+1} .
\end{gathered}
$$

Therefore,

$$
\begin{aligned}
& T[S(m) ; g(m)]=\frac{\sum_{k=0}^{m} 2^{-k}-\frac{2^{m(m-1)}}{2 m+1} \sum_{k=0}^{m^{2}} 2^{-k}}{1-\frac{2^{m(m-1)}}{2 m+1}} \\
& =\frac{2 m+1}{2 m+1-2^{m(m+1)}} \sum_{k=0}^{m} 2^{-k}-\frac{2^{m(m+1)}}{2 m+1-2^{m(m+1)}} \sum_{k=0}^{m^{2}} 2^{-k} .
\end{aligned}
$$


For $m=2$,

$$
T[S(2) ; g(2)] \doteq 1.9534
$$

which is in error by about 0.0466 .

But

$$
S(4)=1.9375
$$

which is in error by 0.0625 . The use of this particular $g$ has led to only a slightly better approximation. It is also interesting to note that $R[m ; g(m)] \rightarrow \infty$ as $m \rightarrow \infty$.

Now let us consider $g(m)=m-3$ and the same series. Then

$$
\begin{gathered}
a(m)=2^{-m} \\
a[g(m)]=8\left(2^{-m}\right) \text { and } \\
R[m ; g(m)]=\frac{1}{8} .
\end{gathered}
$$

Therefore,

$$
\begin{aligned}
T[S(m) ; g(m)] & =\frac{\sum_{k=0}^{m} 2^{-k}-\frac{1}{8} \sum_{k=0}^{m-3} 2^{-k}}{1-\frac{1}{8}} \\
& =\frac{8}{7} \sum_{k=0}^{m} 2^{-k}-\frac{1}{7} \sum_{k=0}^{m-3} 2^{-k} \\
& =\frac{1}{7}\left[\sum_{k=0}^{m} 2^{-k+3}-\sum_{k=3}^{m} 2^{-k+3}\right] \\
& =\frac{14}{7}=2 .
\end{aligned}
$$

which is the correct answer for any value of $m \geqslant 3$.

EXAMPLE 2.2.: Let

$$
S(m)=\sum_{k=1}^{m} \frac{(-1)^{k+1}}{k} \rightarrow \ln 2 \text { as } n \rightarrow \infty
$$

and let $g(m)=m-1$. Then

$$
\begin{gathered}
a(m)=(-1)^{m+1} / m, \\
a[g(m)]=(-1)^{m} /(m-1), \text { and } \\
R[m ; g(m)]=-\frac{m-1}{m} \rightarrow-1 \text { as } m \rightarrow \infty .
\end{gathered}
$$

Therefore,

$$
T[S(m) ; g(m)]=\frac{m}{2 m-1} \sum_{k=1}^{m} \frac{(-1)^{k+1}}{k}-\frac{1-m}{2 m-1} \sum_{k=1}^{m=1} \frac{(-1)^{k+1}}{k}
$$

For $m=4$,

$$
T[S(4) ; g(4)] \doteq 0.69048,
$$


with an error of about 0.00267 , whereas

$$
S(4) \doteq 0.58333
$$

with an error of about 0.10982 .

\section{The $T_{+m}$ Transformation}

From the above two simple examples it is clear that the choice of $g$ can significantly effect the performance of $T$.

For this reason we will now consider a more specific type of $T$ transformation. We do so by determining $g$ such that $T[S(n) ; g(n)]$ is exact when $a(n)=r^{n}$, i.e., such that the transformation is exact on geometric series. In regard to this we have the following theorem.

THEOREM 3.1: If $\mathrm{a}(\mathrm{n})=\mathrm{r}^{\mathrm{n}},|\mathrm{r}|<1$, then a necessary and sufficient condition for $\mathrm{T}$ to be exact, i.e., $\mathrm{T}[\mathrm{S}(\mathrm{n}) ; \mathrm{g}(\mathrm{n})] \equiv \mathrm{S}$, when $n$ is sufficiently large, is that $\mathrm{g}(\mathrm{n})=\mathrm{n}-\mathrm{m}>0$.

Proof:

$$
T[S(n) ; g(n)]=S+\frac{-\sum_{k=n+1}^{\infty} r^{k}+R(n) \sum_{k=g(n)+1}^{\infty} r^{k}}{1-R(n)} .
$$

Therefore $T$ is exact if and only if

$$
-\sum_{k=n+1}^{\infty} r^{k}+R(n) \sum_{k=g(n)+1}^{\infty} r^{k}=-\frac{r^{n+1}}{1-r}+\frac{r^{n+1}}{(1-r)[g(n+1)-g(n)}=0
$$

when $n>N$. The latter implies that

$$
g(n+1)-g(n)=1 \text { when } n>N .
$$

Since $g$ is a positive, integer valued function, (3.3) implies

$$
g(n)=n-m>0 .
$$

Substitution of (3.4) in (3.1) shows the sufficiency.

This leads us to the following important special case which we will set apart by a separate definition.

Definition 3.1.: We define the $\mathrm{T}_{+\mathrm{m}}$ transformation by

$$
\mathrm{T}_{+\mathrm{m}}[\mathrm{S}(\mathrm{n}+\mathrm{m})] \equiv \mathrm{T}[\mathrm{S}(\mathrm{n}+\mathrm{m}) ; \mathrm{n}]=\frac{\mathrm{S}(\mathrm{n}+\mathrm{m})-\mathrm{R}(\mathrm{n}+\mathrm{m}, \mathrm{n}) \mathrm{S}(\mathrm{n})}{1-\mathrm{R}(\mathrm{n}+\mathrm{m}, \mathrm{n})} .
$$

For brevity we will adopt the notation $\mathrm{R}(\mathrm{n} ; \mathrm{m})$ for $\mathrm{R}(\mathrm{n}+\mathrm{m}, \mathrm{n})$, i.e.,

$$
T_{+m}[S(n+m)]=\frac{S(n+m)-R(n ; m) S(n)}{1-R(n ; m)},
$$

where

$$
\mathrm{R}(\mathrm{n} ; \mathrm{m})=\frac{\mathrm{a}(\mathrm{n}+\mathrm{m})}{\mathrm{a}(\mathrm{n})}
$$

Some alternative forms of (3.6) will also be used. They are:

$$
\begin{gathered}
T_{+m}[S(n+m)]=S(n)+\frac{S(n+m)-S(n)}{1-R(n ; m)} . \\
T_{+m}[S(n+m)]=S-\frac{1}{1-R(n ; m)}\{S-S(n+m)-R(n ; m)[S-S(n)]\}
\end{gathered}
$$


and

$$
T_{+m}[S(n+m)]=\frac{S(n) S(n+m-1)-S(n+m) S(n-1)}{S(n)-S(n-1)-S(n+m)+S(n+m-1)}
$$

We can also write, for $\mathrm{n} \geqslant 2$,

$$
\begin{gathered}
T_{+m}[S(n+m)]-T_{+m}[S(n-1+m)] \\
=[S(n+m)-S(n)]\left[\frac{1}{1-R(n ; m)}-\frac{1}{1-R(n-1 ; m)}\right]=b(n) .
\end{gathered}
$$

Therefore we have the following partial sum:

$$
\begin{gathered}
\mathrm{T}_{+\mathrm{m}}[\mathrm{S}(\mathrm{n}+\mathrm{m})]=\sum_{\mathrm{k}=1}^{\mathrm{n}} \mathrm{b}(\mathrm{k}) \text {, where } \\
\mathrm{b}(\mathrm{l})=\mathrm{T}_{+\mathrm{m}}[\mathrm{S}(\mathrm{l}+\mathrm{m})] \text { and } \mathrm{b}(\mathrm{k}) \text { is defined by }(3.11) \text { for } \mathrm{k}=2,3, \ldots
\end{gathered}
$$

A case of particular importance is the case where $\mathrm{m}=1$, although this is by no means the only case of interest here. When $\mathrm{m}=1$ we have

$$
\begin{aligned}
T_{+1}[S(n+1)] & =\frac{S(n+1)-R(n ; 1) S(n)}{1-R(n ; 1)} \\
& =\frac{S(n+1) S(n-1)-S^{2}(n)}{S(n+1)+S(n-1)-2 S(n)}, n>1 .
\end{aligned}
$$

The transformation defined by (3.14) was first introduced by Aitken in [1]. It was later studied extensively by S. Lubkin in [11] and D. Shanks in [12].

Let us consider the following two examples which justify (1) our interest in $T_{+1}[S(n+1)]$ and (2) our interest in $T_{+m}[S(n+m)]$ when $m \neq 1$.

EXAmple 3.1: Consider the Liebnitz expansion for $\pi$. That is,

$$
\pi=4-\frac{4}{3}+\frac{4}{5}-\frac{4}{7}+\ldots
$$

From a numerical viewpoint (3.16) is essentially worthless as it stands since it takes more than $4 \times 10^{7}$ terms to obtain eight figure accuracy. It is a remarkable fact, however, that eight figure accuracy can be obtained from only the first 10 terms by means of $T_{+1}[S(n+1)]$. This was demonstrated in [12] by repeated application of $T_{+1}$. The procedure is indicated below on the first five terms of (3.16).

TABLE 1

\begin{tabular}{l|c|c|c}
\hline \hline$n$ & $S(n)$ & $T_{+1}$ & $T_{+1}^{2}$ \\
\hline & & & \\
1 & 4.0000000 & & \\
2 & 2.6666667 & 3.1666667 & \\
3 & 3.4666667 & 3.1333333 & 3.1421053 \\
4 & 2.8952381 & 3.1452381 & \\
5 & 3.3396825 & & \\
\hline
\end{tabular}

EXAMPLE 3.2: Consider now the same sum in the form

$$
4 \sum_{n=1}^{\infty} \frac{\sin (n \pi / 2)}{n}=\pi
$$


Thus we have

$$
\pi=4+0-\frac{4}{3}+0+\frac{4}{5}+0-\frac{4}{7}+\ldots
$$

In this case $T_{+1}[S(n+1)]$ is not worthwhile since $T_{+1}^{k}[S(n+1)]=T_{+1}^{k-1}[S(n+1)]=S(n+1)$ for every $k$ for which the relations are properly defined. Of course we can apply $T_{+1}[S(n+1)]$, as we already have, if we delete the zeros. However in general it may not be a simple matter to determine how to rearrange a series so that $T_{+1}[S(n+1)]$ is useful. For example if we consider the series $\sum_{n=1}^{\infty} \frac{1}{n^{2}}\left(\sin \frac{n \pi}{p}\right)$, then when $p$ is an integer greater than 2 the problem of rearranging the series so as to apply $T_{+1}$ becomes unmanageable due to the difficulty of writing the general term when the zeros are deleted. However the problem is easily handled by selecting $m=p$ in the $T_{+m}$ transformation. Thus a better way to handle the above problem is as follows. Note that

$$
\begin{aligned}
R(n ; m)=\frac{a(n+m)}{a(n)} & =\frac{\sin [(n+m) \pi / 2]}{\sin (n \pi / 2)} \frac{n}{n+m} \\
& =\frac{\sin \cdot(n \pi / 2) \cos (m \pi / 2)+\sin (m \pi / 2) \cos (n \pi / 2)}{\sin (\pi / 2)} \frac{n}{n+m} \\
& =\left[\cos (m \pi / 2)^{\circ}+\cot (n \pi / 2) \sin (m \pi / 2)\right] \frac{n}{n+m} .
\end{aligned}
$$

Thus, if $m=1, R(n ; 1)$ does not exist in general. But, if $m=2, R(n ; 2)$ exists for every $n$ and we obtain the following table from applying $T_{+2}$ repeatedly to the first ten terms of (3.18). That is, using only the partial sums we used in table 1.

TABLE 2

\begin{tabular}{r|c|c|c|c}
\hline$n$ & $S(n)$ & $T_{+2}$ & $T_{+2}^{2}$ & $T_{+2}^{3} \ldots$ \\
\hline & & & & \\
1 & 4 & 3.1111111 & 3.1444444 & 3.1417363 \\
2 & 4 & 3.1666667 & 3.1425851 & \\
3 & 2.6666667 & 3.1466667 & 3.1404762 & \\
4 & 2.6666667 & 3.1333333 & 3.1413119 & \\
5 & 3.4666667 & 3.1401361 & & \\
6 & 3.4666667 & 3.1452381 & & \\
7 & 2.8952381 & 3.1421517 & & \\
8 & 2.8952381 & & & \\
9 & 3.3396825 & & & \\
10 & 3.3396825 & & & \\
\hline
\end{tabular}

It should be mentioned that the form (3.10) was utilized in constructing table 2 since this simplifies the repeated application.

As already mentioned the results in table 1 were first given in [12]. In that same paper the author remarks that if (3.16) is written in the form (3.18), then $T_{+1}\lfloor S(n+1)]$ is not directly applicable. In this example we have seen, however, that $T_{+m}$ is directly applicable when $m=2$.

From the above it is clear that $T_{+m}[S(n+m)]$ bears some investigation in general. This will be the purpose of the next several pages. The case $m=1$ will not be considered separately since it has been extensively studied in the existing literature. It will first be necessary to introduce some results which will be useful in proving these theorems.

TheOrem 3.2: Let $\mathrm{A}(\mathrm{n})$ and $\mathrm{B}(\mathrm{n})$ be sequences such that $\lim \mathrm{A}(\mathrm{n})=0$ and $\mathrm{B}(\mathrm{n})$ is monotone and converges to zero as $\mathrm{n} \rightarrow \infty$. If $n \rightarrow \infty$

$$
\lim _{n \rightarrow \infty} \frac{A(n)-A(n-1)}{B(n)-B(n-1)}
$$


exists, finite or infinite, then

$$
\lim _{n \rightarrow \infty} \frac{A(n)}{B(n)}=\lim _{n \rightarrow \infty} \frac{A(n)-A(n-1)}{B(n)-B(n-1)} .
$$

Proof; See [1].

THEOREM 3.3: If

(i) $\mathrm{S}(\mathrm{n})$ is a monotone sequence with limit

$$
\mathrm{S}=\sum_{\mathrm{n}=1}^{\infty} \mathrm{a}(\mathrm{n})
$$

(ii) $\mathrm{m}$ is a nonnegative integer and

$$
\mathrm{R}_{\mathrm{m}}=\lim _{\mathrm{n} \rightarrow \infty} \frac{a(n+\mathrm{m})}{\mathrm{a}(\mathrm{n})}
$$

then

$$
\lim _{n \rightarrow \infty} \frac{S-S(n+m)}{S-S(n)}=R_{m}
$$

Proof: Since $S(n)$ is a monotone sequence, $S-S(n)$ is a monotone sequence which converges to zero. Thus we can apply Theorem 3.2 and

$$
\begin{gathered}
\lim _{n \rightarrow \infty} \frac{S-S(n+m)-S+S(n+m-1)}{S-S(n)-S+S(n-1)}=\lim _{n \rightarrow \infty} \frac{S(n+m)-S(n+m-1)}{S(n)-S(n-1)} \\
=\lim _{n \rightarrow \infty} \frac{a(n+m)}{a(n)} \\
=\lim _{n \rightarrow \infty} \frac{S-S(n+m)}{S-S(n)} .
\end{gathered}
$$

It should be noted that Theorem 3.3 can be restated in the form

$$
\lim _{n \rightarrow \infty} \frac{\sum_{k=n+m+1}^{\infty} a(k)}{\sum_{k=n+1}^{\infty} a(k)}=\lim _{n \rightarrow \infty} \frac{a(n+m)}{a(n)} .
$$

This result is directly analogous to applying L'Hospitals theorem to improper integrals.

A special case of the above theorem arises when the series consists of terms of constant sign when $n$ is sufficiently large. When a series is alternating, $S(n)$ will generally not be monotone for any range of $n$ and the above theorem does not apply. However a result similar to Theorem 3.3 can be obtained when the terms are decreasing in absolute value.

THEOREM 3.4: If

$$
\text { (i) } \mathrm{S}=\sum_{n=1}^{\infty} \mathrm{a}(\mathrm{n}), \mathrm{a}(\mathrm{n})=(-1)^{\mathrm{n}} \mathrm{C}(\mathrm{n}) \text {, }
$$

where $\mathrm{C}(\mathrm{n})>\mathrm{C}(\mathrm{n}+1)>0$,

$$
\text { (ii) } R(n+1)=\frac{a(n+1)}{a(n)} \rightarrow R \neq-1 \text {, }
$$


and

(iii) $\mathrm{m}$ is a positive integer,

then

$$
\lim _{n \rightarrow \infty} \frac{S-S(n+m)}{S-S(n)}=\lim _{n \rightarrow \infty} \frac{a(n+m)}{a(n)}=R^{m} .
$$

Moreover, if $R=-1$ and

$$
\lim _{n \rightarrow \infty} \frac{1+R(n ; 1)}{1+R(n-1 ; 1)}=1,
$$

thèn the above results hold.

Proof: Consider the case $m=1$. By hypothesis, $S$ converges and the sequences $S(2 n)$ and $S(2 n+1)$ are decreasing and increasing respectively. Therefore $S(2 n)-S$ and $S-S(2 n+1)$ decrease to zero. But

$$
\begin{aligned}
\frac{[S(2 m+1)-S]-[S(2 m-1)-S]}{[S(2 m)-S]-[S(2 m-2)-S]} & =\frac{a(2 n)+a(2 n+1)}{a(2 n-1)+a(2 n)} \\
& =R(2 m-1,1)\left[\frac{1+R(2 m, 1)}{1+R(2 m-1,1)}\right],
\end{aligned}
$$

which converges to $R$ under the conditions stated. Applying Theorem 3.2, it follows that

$$
\lim _{n \rightarrow \infty} \frac{S-S(2 n+1)}{S-S(2 n)}=R .
$$

The same argument can be applied to the quotient $[S-S(2 n+2)] /[S-S(2 n+1)]$ and since both of these sequences converge to $R$ it follows that

$$
\lim _{n \rightarrow \infty} \frac{S-S(n+1)}{S-S(n)}=R
$$

In the general case we note that

$$
\frac{a(n+m)}{a(n)}=\frac{a(n+1)}{a(n)} \cdot \frac{a(n+2)}{a(n+1)} \cdot \frac{a(n+3)}{a(n+2)} \cdot \cdots \frac{a(n+m)}{a(n+m-1)},
$$

and thus,

$$
\lim _{n \rightarrow \infty} \frac{a(n+m)}{a(n)}=R^{m}
$$

Also

$$
\frac{S-S(n+m)}{S-S(n)}=\frac{S-S(n+1)}{S-S(n)} \cdot \frac{S-S(n+2)}{S-S(n+1)} \cdots \frac{S-S(n+m)}{S-S(n+m-1)},
$$

and referring to the case $m=1$ we see that

$$
\lim _{n \rightarrow \infty} \frac{S-S(n+m)}{S-S(n)}=R^{m}
$$

and the theorem follows.

THEOREM 3.5: For every $\mathrm{m}$ for which there exists an $\mathrm{M}>0$ such that $|1-\mathrm{R}(\mathrm{n} ; \mathrm{m})| \geqslant \mathrm{M}$ for $\mathrm{n}$ sufficiently large, $\mathrm{T}_{+\mathrm{m}}[\mathrm{S}(\mathrm{n}+\mathrm{m})]$ converges to $\mathrm{S}$.

Proof: The result is a special case of Theorem 2.1.

CoRollary 3.1: If $\lim _{n \rightarrow \infty} \mathrm{R}(\mathrm{n} ; \mathrm{m})=\mathrm{R}_{\mathrm{m}} \neq 1$, then $\mathrm{T}_{+\mathrm{m}}[\mathrm{S}(\mathrm{n}+\mathrm{m})]$ converges to $\mathrm{S}$.

When $m=1$ a stronger theorem than the above can be given. This is the case for many of the following theorems. For a discussion of such theorems when $m=1$ see [11].

A further comment should be made in regard to Theorem 3.5. That is, in general $T_{+m}[S(n+m)]$, is not a regular transformation. Thus $S(n)$ may converge as $n \rightarrow \infty$ and $T_{+m}[S(n+m)]$ diverge. Theorem 3.5 shows this can only occur when $R_{m}=1$ or when $R_{m}$ fails to exist. 
LEMma 3.1: If $\mathrm{a}(\mathrm{n})$ is monotone then $\mathrm{n}[\mathrm{S}(\mathrm{n}+\mathrm{m})-\mathrm{S}(\mathrm{n})] \rightarrow 0$ as $\mathrm{n} \rightarrow \infty$.

Proof: Since $S$ converges and $a(n)$ is monotone, then $n \cdot a(n) \rightarrow 0$. Thus $n a(n+p)+p a(n+p)$ $=(n+p) a(n+p) \rightarrow 0$ for each integer $p \geqslant 0$ and since $a(n+p) \rightarrow 0$ as $n \rightarrow \infty$ it follows that $n a(n+p) \rightarrow 0$ as $n \rightarrow \infty$. Hence $n[S(n+m)-S(n)]=n a(n+1)+\ldots+n a(n+m) \rightarrow 0$ as $n \rightarrow \infty$.

THEOREM 3.6: If $\mathrm{a}(\mathrm{n})$ is monotone and $\lim _{n \rightarrow \infty} \mathrm{T}_{+\mathrm{m}}[\mathrm{S}(\mathrm{n}+\mathrm{m})]=\mathrm{L}(\mathrm{m})$, then $\mathrm{L}(\mathrm{m})=\mathrm{S}$.

Proof: Suppose the theorem is false. Then

as $n \rightarrow \infty$. Hence

$$
T_{+\mathrm{m}}[S(n+m)-S(n)]=\frac{S(n+m)-S(n)}{1-R(n ; m)} \rightarrow L(m)-S \neq 0
$$

$$
\frac{n[S(n+m)-S(n)]}{n[1-R(n ; m)]} \rightarrow L(m)-S \neq 0 \text { as } n \rightarrow \infty .
$$

But, by lemma 3.1, $n[S(n+m)-S(n)] \rightarrow 0$ as $n \rightarrow \infty$ and hence we must have $n[1-R(n ; m)] \rightarrow 0$ as $n \rightarrow \infty$.

Now if we let $b(n)=a(n m)$, then

$$
\frac{b(n+1)}{b(n)}=\frac{a(n m+m)}{a(n m)}=R(n m ; m)>0,
$$

and thus $n m[1-R(n m ; m)] \rightarrow 0$ as $n \rightarrow \infty$ or

$$
n[1-R(n m ; m)]=n\left[1-\frac{b(n+1)}{b(n)}\right] \rightarrow 0
$$

as $n \rightarrow \infty$. Therefore, by Raabe's test, the series

$$
\sum_{n=1}^{\infty} b(n)=\sum_{n=1}^{\infty} a(n m)
$$

diverges. But the latter is false since $S(n)$ converges absolutely as $n \rightarrow \infty$ and $\sum_{n=1}^{\infty} b(n)$ is asubseries of $S$. The theorem therefore follows.

Lemma 3.2: If $\mathrm{a}(\mathrm{n})=0\left(\mathrm{n}^{-\alpha}\right), \quad \alpha>1$, as $\mathrm{n} \rightarrow \infty$, then $\mathrm{n}[\mathrm{S}(\mathrm{n}+\mathrm{m})-\mathrm{S}(\mathrm{n})] \rightarrow 0$ as $\mathrm{n} \rightarrow \infty$.

Proof: By hypothesis,

$$
\begin{aligned}
|n[S(n+m)-S(n)]| & \leqslant n|a(n+1)|+n|a(n+2)|+\ldots+n|a(n+m)| \\
& \leqslant n m M n^{-\alpha}=m M n^{-\alpha+1}
\end{aligned}
$$

for some $M>0$, provided $n$ is sufficiently large. The lemma then clearly follows from (3.40).

THEOREM 3.7: If $\mathrm{a}(\mathrm{n})=0\left(\mathrm{n}^{-\alpha}\right), \alpha>1$, as $\mathrm{n} \rightarrow \infty$ and $\mathrm{T}_{+\mathrm{m}}[\mathrm{S}(\mathrm{n}+\mathrm{m})]$ converges, then $\mathrm{T}_{+\mathrm{m}}[\mathrm{S}(\mathrm{n}+\mathrm{m})]$ converges to $\mathrm{S}$ as $\mathrm{n} \rightarrow \infty$.

Proof: The proof is the same as in Theorem 3.6 with the exception that (3.39) converges because $a(n)=0\left(n^{-\alpha}\right)$.

THEOREM 3.8: If $\lim \mathrm{R}(\mathrm{n} ; \mathrm{m})=\mathrm{R}_{\mathrm{m}} \neq 0,1$, then $\mathrm{T}_{+\mathrm{m}}[\mathrm{S}(\mathrm{n}+\mathrm{m})]$ converges more rapidly than $\mathrm{S}(\mathrm{n}+\mathrm{m})$ if and only if

$$
\lim _{n \rightarrow \infty} \frac{S-S(n+m)}{S-S(n)}=R_{m}
$$

Proof: The result follows from Theorem 2.2.

COROLLARY 3.2: If $\mathrm{a}(\mathrm{n})$ is of constant sign for $\mathrm{n}$ sufficiently large and $\mathrm{R}_{\mathrm{m}}$ exists but $\mathrm{R}_{\mathrm{m}} \neq 0,1$, then $\mathrm{T}_{+\mathrm{m}}[\mathrm{S}(\mathrm{n}+\mathrm{m})]$ converges more rapidly than $\mathrm{S}(\mathrm{n}+\mathrm{m})$.

Proof: The corollary follows from Theorems 3.8 and 3.3.

Corollary 3.3: If $\mathrm{a}(\mathrm{n})=(-1)^{\mathrm{n}} \mathrm{C}(\mathrm{n}), \mathrm{C}(\mathrm{n})>\mathrm{C}(\mathrm{n}+1)>0$ and $\mathrm{R}_{\mathrm{m}}$ exists but $\mathrm{R}_{\mathrm{m}} \neq 0,-1$, then $\mathrm{T}_{+\mathrm{m}}[\mathrm{S}(\mathrm{n}+\mathrm{m})]$ converges more rapidly than $\mathrm{S}(\mathrm{n}+m)$.

PRoof: The corollary follows from Theorems 3.8 and 3.4. 
In the above theorems we have established conditions under which (1) $T_{+m}[S(n+m)] \rightarrow S$ and (2) $T_{+m}[S(n+m)] \rightarrow S$ more rapidly than $S(n+m)$ as $n \rightarrow \infty$. In general our theorems concerning the Iatter were less general than those concerning the former. Thus in Theorems 3.5 and 3.6 we did not find it necessary to require even the existence of the $\lim R(n ; m)$. On the other hand, in Theorem 3.8, we required not only the existence of $\lim _{n \rightarrow \infty} R(n ; m)$, but that it be different from 0 or 1 . In the case $R_{m}=0, T_{+m}[S(n+m)]$ may or may not converge more rapidly than $S(n+m)$. This is best seen by the following examples.

ExAmple 3.3: Let $S(n)=1 / n$ !. Then $S(n) \rightarrow 0$ and $S(n+1) / S(n) \rightarrow 0$ as $n \rightarrow \infty$. Hence $\lim R(n ; 1)=0$ by Theorem 3.3. Thus we see in this case that $R_{1}=0$ and $S(n+1)$ converges more rapidly than $S(n)$. We have included this example to emphasize that our interest when $R_{1}=0$ should be centered on comparing the rate of convergence of $T_{+m}[S(n+m)]$ with $S(n+m)$ rather than $S(n)$, since in this case $S(n+m)$ and $S(n)$ do not necessarily converge at the same rate. Note that when either Theorem 3.3 or Theorem 3.4 hold that $S(n+m)$ converges more rapidly than $S(n)$ if $R_{1}=0$ and at the same rate as $S(n)$ if $R_{1} \neq 0$.

EXAMPLE 3.4: Let $a(n)=1 / n$ ! and $m=1$. Then $R_{1}=0$ and since $A(n)=S-S(n+1)$ is a deceasing sequence converging to 0 , we can apply Theorem 3.2 to $A(n)$ and $B(n)=S-T_{+m}[S(n$ $+m)]$. Thus, using (3.11), we have

$$
\begin{aligned}
\frac{B(n)-B(n-1)}{A(n)-A(n-1)}=\frac{b(n)}{a(n+1)} & =\frac{a(n)}{a(n+1)}\left[\frac{R(n ; 1)-R(n-1 ; 1)}{(1-R(n ; 1))(1-R(n-1 ; 1))}\right] \\
& =\left[\frac{1-\frac{R(n-1 ; 1)}{R(n ; 1)}}{(1-R(n ; 1))(1-R(n-1 ; 1))}\right] \\
& =\frac{1-\frac{n+1}{n}}{(1-R(n ; 1))(1-R(n-1 ; 1))}
\end{aligned}
$$

as $n \rightarrow \infty$.

Hence

$$
\lim _{n \rightarrow \infty} \frac{S-T_{+1}[S(n+1)]}{S-S(n+1)}=0
$$

and $T_{+1}[S(n+1)]$ converges more rapidly than $S(n+1)$.

EXAMPLE 3.5: Let $m=1$ and

$$
a(n)=\frac{2}{(n+1) ! 2^{\left(n^{2}+3 n-4\right) / 2}}
$$

Then

$$
R(n ; 1)=\frac{a(n+1)}{a(n)}=\frac{1}{(n+2) 2^{n+2}},
$$

and therefore $R_{1}=0$.

Moreover

$$
\frac{R(n-1 ; 1)}{R(n ; 1)}=\frac{(n+2) 2^{n+2}}{(n+1) 2^{n+1}} \rightarrow 2
$$

as $n \rightarrow \infty$.

Therefore, using the notation of the previous example, we have

$$
\frac{B(n)-B(n-1)}{A(n)-A(n-1)}=\frac{1-\frac{R(m-1 ; 1)}{R(m ; 1)}}{(1-R(m ; 1))(1-R(m-1 ; 1))} \rightarrow-1
$$

as $n \rightarrow \infty$. 
Hence,

$$
\lim _{n \rightarrow \infty} \frac{S-T_{+1}[S(n+1)]}{S-S(n+1)}=-1
$$

and $T_{+1}[S(n+1)]$ and $S(n+1)$ converge with the same order of rapidity. Note that in the same manner one has

$$
\lim _{n \rightarrow \infty} \frac{S-T_{+1}[S(n+1)]}{S-S(n)}=\lim _{1 n \rightarrow \infty} \frac{R(n ; 1)-R(n-1 ; 1)}{(1-R(n ; 1))(1-R(n-1 ; 1))}=0,
$$

so that $T_{+1}[S(n+1)]$ does converge more rapidly than $S(n)$ in this case.

EXAMPLE 3.6: Let $m=1$ and

$$
a(n)=\frac{1}{n ! 2^{n^{3}}} .
$$

Then

$$
R(n ; 1)=\frac{1}{(n+1) 2^{3 n^{2}+3 n+1}} \rightarrow 0
$$

as $n \rightarrow \infty$ and by Theorem 3.3

$$
\frac{S-S(n+1)}{S-S(n)}=1-\frac{a(n+1)}{S-S(n)} \rightarrow 0
$$

as $n \rightarrow \infty$.

Moreover

$$
\frac{R(n+1 ; 1)}{R(n ; 1)}=\left(\frac{n+1}{n+2}\right)\left(\frac{1}{2^{6 n} 6}\right) \rightarrow 0
$$

as $n \rightarrow \infty$.

But

$$
\frac{S-S(n+1)}{S-T_{+1}[S(n+1)]}=\frac{1}{1-\left[\frac{a(n+2)}{S-S(n+1)}\right]\left[\frac{1}{1-R(n ; 1)}\right]\left[\frac{R(n ; 1)}{R(n+1 ; 1)}\right]},
$$

and thus (3.52) has the limit zero as $n \rightarrow \infty$ so that $S(n+1)$ converges more rapidly than $T_{+1}[S(n+1)]$.

In the previous examples we have seen that if $R_{m}=0$, then the $T_{+m}$ transform may or may not be useful. We will therefore now embark on a series of theorems which are useful in ascertaining the value of $T_{+m}$ in that situation. We begin by listing a sequence of lemmas most of which are obvious or very easily proven.

LEMMA 3.3: If $\mathrm{R}(\mathrm{n} ; \mathrm{m})$ converges to $\mathrm{R}_{\mathrm{m}}$, then $\left|\mathrm{R}_{\mathrm{m}}\right| \leqslant 1$.

Proof: Suppose the lemma is false. Then $\left|R_{m}\right|>1$ and therefore there exists an $N$ such that $|R(n ; m)|>1$ where $n \geqslant N$, i.e., $|a(n+m)|>|a(n)|$. Thus, $\lim _{n \rightarrow \infty} a(n) \neq 0$, so that $S(n)$ does not converge as $n \rightarrow \infty$. This is a contradiction and the theorem follows.

LEMMA 3.4: If $\mathrm{R}(\mathrm{n} ; \mathrm{l}) \rightarrow \mathrm{R}$, then $\mathrm{R}(\mathrm{n} ; \mathrm{m}) \rightarrow \mathrm{R}^{\mathrm{m}}$ as $\mathrm{n} \rightarrow \infty$, i.e., if $\mathrm{R}_{1}=\mathrm{R}$ then $\mathrm{R}_{\mathrm{m}}=\mathrm{R}^{\mathrm{m}}$.

PROOF: The result follows easily by noting that

LEMMA 3.5:

$$
\begin{aligned}
R(n ; m) & =\frac{a(n+m)}{a(n)}=\frac{a(n+1)}{a(n)} \cdot \frac{a(n+2)}{a(n+1)} \ldots \frac{a(n+m)}{a(n+m-1)} \\
& =R(n ; 1) \cdot R(n+1 ; 1) . . R(n+m ; 1) .
\end{aligned}
$$

$$
\begin{aligned}
R(n ; \mathrm{m}) & =\frac{\mathrm{a}(\mathrm{n}+\mathrm{m})}{\mathrm{a}(\mathrm{n})} \\
& =\frac{\mathrm{a}(\mathrm{n}+\mathrm{m}+1)}{\mathrm{a}(\mathrm{n}+\mathrm{l})} \cdot \frac{\mathrm{a}(\mathrm{n}+\mathrm{m})}{\mathrm{a}(\mathrm{n}+\mathrm{m}+1)} \cdot \frac{\mathrm{a}(\mathrm{n}+1)}{\mathrm{a}(\mathrm{n})} \\
& =\frac{\mathrm{R}(\mathrm{n}+1 ; \mathrm{m})}{\mathrm{R}(\mathrm{n}+\mathrm{m} ; \mathrm{l})} \mathrm{R}(\mathrm{n} ; \mathrm{l})
\end{aligned}
$$


LEMMA 3.6:

$$
\frac{\mathrm{R}(\mathrm{n} ; \mathrm{m})}{\mathrm{R}(\mathrm{n}+1 ; \mathrm{m})} \rightarrow \mathrm{A} \text { as } \mathrm{n} \rightarrow \infty
$$

if and only if

$$
\lim _{n \rightarrow \infty} \frac{R(n ; 1)}{R(n+m ; 1)}=A .
$$

Proof: This lemma follows immediately from Lemma 3.5.

LEMMA 3.7: If

and

$$
\lim _{n \rightarrow \infty} \frac{R(n ; 1)}{R(n+m ; 1)} \neq 1
$$

$$
\lim _{n \rightarrow \infty} R(n ; m)=R_{m}, R_{m} \text { finite }
$$

then $\mathrm{R}_{\mathrm{m}}=0$.

Proof: The lemma is obvious.

LEMMA 3.8: If $\mathrm{a}(\mathrm{n})$ is of constant sign and

$$
\lim _{n \rightarrow \infty} \frac{R(n ; 1)}{R(n+m ; 1)}=A \neq 1,
$$

then

$$
\lim _{n \rightarrow \infty} R(n ; 1)=0
$$

where $\dot{A}$ is finite or infinite.

Proof: Since $A(n)$ is of constant sign, it follows that $R(n ; 1)>0$. Also

$$
\frac{R(n ; 1)}{R(n+m ; 1)}>1
$$

or

$$
\frac{R(n ; 1)}{R(n+m ; 1)}<1
$$

for $n$ sufficiently large. However (3.62) and (3.59) imply that $S(n)$ diverges as $n \rightarrow \infty$ and hence cannot hold. Thus, for $n$ sufficiently large, say $n \geqslant N$, we have

$$
\begin{aligned}
& R(n ; 1)>R(n+m ; 1)>R(n+2 m ; 1)>\ldots>0 \\
& R(n+1 ; 1)>R(n+m+1 ; 1)>\ldots>\ldots>0 \\
& . \\
& . \\
& R(n+m-1)>R(n+2 m-1 ; 1)>\ldots>0,
\end{aligned}
$$

and since $A \neq 1$, each subsequence in (3.63) converges to 0 . Thus $R(n ; 1) \rightarrow 0$ as $n \rightarrow \infty$.

LeMмa 3.9: If $a(n)=(-1)^{n} C(n), C(n)>C(n+1)>0$, and $\lim _{n \rightarrow \infty} \frac{R(n ; 1)}{R(n+m ; 1)}=A \neq 1$, then $\lim _{n \rightarrow \infty} R(n ; 1)=0$.

Proof: The proof is similar to that of Lemma 3.8.

Lemma 3.10:

$$
\begin{aligned}
S(n+m)-S(n)= & a(n+1)[1+R(n+1 ; 1)+R(n+1 ; 1) R(n+2 ; 1)+\ldots . \\
& +R(n+1 ; 1) \ldots R(n+m-1 ; 1)] \\
= & a(n+1)[1+R(n+1 ; 1)+\ldots+R(n+1 ; m-1)]
\end{aligned}
$$


Proof: The result follows by noting that

$$
\begin{array}{r}
a(n+1)\left[1+\frac{a(n+2)}{a(n+1)}+\ldots+\frac{a(n+m)}{a(n+1)}\right] \\
=a(n+1)\left[1+\frac{a(n+2)}{a(n+1)}+\frac{a(n+3) a(n+2)}{a(n+2) a(n+1)}+\ldots+\frac{a(n+m)}{a(n+m-1)}\right. \\
\left.\cdot \frac{a(n+m-1)}{a(n+m-2)} \ldots \frac{a(n+2)}{a(n+1)}\right] .
\end{array}
$$

LEMMA 3.11: If $\mathrm{R}(\mathrm{n} ; 1)$ is bounded by $\mathrm{M}$, then $\frac{\mathrm{S}(\mathrm{n}+\mathrm{m})-\mathrm{S}(\mathrm{n})}{\mathrm{a}(\mathrm{n}+\mathrm{l})}$ is bounded by $\frac{1-\mathrm{M}^{\mathrm{m}}}{1-\mathrm{M}}$ if $\mathrm{M} \neq 1$ and by $\mathrm{m}$ if $\mathrm{M}=1$.

PRoоF: The proof follows immediately from Lemma 3.10.

Note that if $R_{1}$ exists, then it is finite by Lemma 3.3 and hence $R(n ; 1)$ is bounded.

LEMMA 3.12

$$
\frac{S(n+m)-S(n)}{S(n+2 m)-S(n+m)}=\frac{1}{R(n+1 ; m)}\left[\frac{1+\sum_{k=1}^{m-1} \prod_{i=1}^{k} R(n+i ; 1)}{1+\sum_{k=1}^{m-1} \prod_{i=1}^{k} R(n+m+i ; 1)}\right] .
$$

Proof: The lemma follows immediately from Lemma 3.10.

LEMMA 3.13:

$$
\frac{S-S(n+m)}{S-S(n)}=\frac{S-S(n)-S(n+m)+S(n)}{S-S(n)}=1-\frac{S(n+m)-S(n)}{S-S(n)} .
$$

THEOREM 3.9: If either $\mathrm{R}_{1}$ exists or $\mathrm{R}(\mathrm{n} ; 1)$ is bounded, $\mathrm{S}(\mathrm{n})$ is monotone, and if there exists $\mathrm{p}$ and $\mathrm{m}$ such that $\lim _{n \rightarrow \infty} \frac{\mathrm{R}(\mathrm{n} ; \mathrm{l})}{\mathrm{R}(\mathrm{n}+\mathrm{m} ; \mathrm{l})}=1$ and $|1-\mathrm{R}(\mathrm{n} ; \mathrm{m})| \geqslant \mathrm{p}>0$ for $\mathrm{n}$ sufficiently large, then $\mathrm{T}_{+\mathrm{m}}[\mathrm{S}(\mathrm{n}+\mathrm{m})]$ converges more rapidly than $\mathrm{S}(\mathrm{n}+\mathrm{m})$.

Proof: By Lemma 3.11, $\frac{S(n+m)-S(n)}{a(n+1)}$ is bounded. Moreover, $S(n)$ is monotone, so that $S-S(n+m)$ is monotone. Now let $B(n)=S-T_{+m}[S(n+m)]$ and $A(n)=S-S(n+m)$. Then

$$
\begin{aligned}
\frac{B(n+1)-B(n)}{A(n+1)-A(n)} & =\frac{b(n+1)}{a(n+m+1)} \\
& =\frac{S(n+m)-S(n)}{a(n+m+1)}\left\{\frac{R(n+1 ; m)-R(n ; m)}{[1-R(n+1 ; m)][1-R(n ; m)]}\right\} \\
& =\frac{S(n+m)-S(n)}{a(n+1)}\left\{\frac{1-\frac{R(n ; m)}{R(n+1 ; m)}}{[1-R(n+1 ; m)][1-R(n ; m)]}\right\}
\end{aligned}
$$

and by Lemma 3.6, the latter quantity goes to zero as $n \rightarrow \infty$.

Hence,

$$
\lim _{n \rightarrow \infty} \frac{S-T_{+m}[S(n+m)]}{S-S(n+m)}=0
$$

and the theorem follows. One should note that if $m=1$, then the assumption that $R(n ; 1)$ is bounded can be dropped. This follows from (3.67).

Also note that the main difference between this theorem and Theorem 3.8 and its corollaries is that here we have not required $R_{m} \neq 0$. In fact we have not even required the existence of $R_{m}$.

CoROLlaRY 3.4: If $\mathrm{a}(\mathrm{n})$ is of constant sign, $\mathrm{R}_{1}$ exists, $\mathrm{R}_{1} \neq 1$, and if $\lim _{\mathrm{n} \rightarrow \infty} \frac{\mathrm{R}(\mathrm{n} ; \mathrm{l})}{\mathrm{R}(\mathrm{n}+\mathrm{m} ; 1)}=1$, then $\mathrm{T}_{+\mathrm{m}}[\mathrm{S}(\mathrm{n}+\mathrm{m})]$ converges more rapdily than $\mathrm{S}(\mathrm{n}+\mathrm{m})$ as $\mathrm{n} \rightarrow \infty$. 
Proof: The result is an immediate consequence of Theorem 3.9 by noting that $S(n)$ is eventually monotone and $R(n ; m) \rightarrow R_{1}^{m} \neq 1$.

Note that since $R_{1}=0$ implies $R_{m}=0$, then when corollary 3.4 applies $T_{+m}[S(n+m)]$ converges more rapidly than $S(n+m)$ when $R_{m}=0$ if $\lim _{n \rightarrow \infty} \frac{R(n ; 1)}{R(n+m ; 1)}=1$. Another useful theorem in this respect is the following.

Theorem 3.10: If $\mathrm{a}(\mathrm{n})=(-1)^{\mathrm{n}} \mathrm{C}(\mathrm{n}), \mathrm{C}(\mathrm{n})>\mathrm{C}(\mathrm{n}+1)>0, \mathrm{R}_{1} \neq-1$ exists and $\lim _{\mathrm{n} \rightarrow \infty} \frac{\mathrm{R}(\mathrm{n} ; \mathrm{l})}{R(n+m ; 1)}=1$, then $\mathrm{T}_{+\mathrm{m}}[\mathrm{S}(\mathrm{n}+\mathrm{m})]$ converges more rapidly than $\mathrm{S}(\mathrm{n}+\mathrm{m})$.

Proof: The sequence $S-S(2 n+m)$ is monotone and $S-T_{+m}[S(2 n+m)]$ converges to 0 since $R_{m} \neq 1$. Moreover

$$
\begin{aligned}
& \frac{T_{+m}[S(2 n+m)]-T_{+m}[S(2 n-2+m)]}{S(2 n+m)-S(2 n-2+m)}=\frac{b(2 n-1)+b(2 n)}{a(2 n-1+m)+a(2 n)} \\
& =\frac{S(2 n-2+m)-S(2 n-2)}{a(2 n-1+m)+a(2 n+m)}\left\{\frac{R(2 n-1 ; m)-R(2 n-2 ; m)}{[1-R(2 n-1 ; m)][1-R(2 n-2 ; m)]}\right\} \\
& \quad+\frac{S(2 n-1+m)-S(2 n-1)}{a(2 n-1+m)+a(2 n+m)}\left\{\frac{R(2 n ; m)-R(2 n-1 ; m)}{[1-R(2 n ; m)][1-R(n-1 ; m)]}\right\} \\
& =\frac{S(2 n-2+m)-S(2 n-2)}{a(2 n-1)}\left\{\frac{1-\frac{R(2 n-2 ; m)}{R(2 n-1 ; m)}}{[1+R(2 n+m-1 ; 1)][1-R(2 n ; m)][1-R(2 n-1 ; m)]}\right\}
\end{aligned}
$$

Now by Lemma 3.4, $R(n ; m) \rightarrow R_{1}^{m} \neq 1,-1$ as $n \rightarrow \infty$ and therefore by Lemma 3.11 $\frac{S(n+m)-S(n)}{a(n+1)}$ is bounded. Thus by Lemma 3.6, (3.69) converges to zero.

Hence by Theorem 3.2

$$
\lim _{n \rightarrow \infty} \frac{S-T_{+m}[S(2 n+1+m)]}{S-S(n+m)}=0 .
$$

A similar argument may be applied for the quotient

$$
\frac{S-T_{+m}[S(2 n+1+m)]}{S-S(2 n+1+m)}
$$

Thus

$$
\lim _{n \rightarrow \infty} \frac{S-T_{+m}[S(2 n+1+m)]}{S-S(n+m)}=0,
$$

and the theorem follows.

In the previous two theorems we have shown that for series of constant sign or certain alternating series that a sufficient condition that $T_{+m}[S(n+m)]$ converge more rapidly than $S(n+m)$ when $\lim _{n \rightarrow \infty} R(n ; 1)=0$ is that $\lim _{n \rightarrow \infty} \frac{R(n ; 1)}{R(n+m ; 1)}=1$. We will now show that the condition is necessary for these types of series.

THEOREM 3.11: If $\mathrm{a}(\mathrm{n})$ is of constant sign and $\lim _{\mathrm{n} \rightarrow \infty} \frac{\mathrm{R}(\mathrm{n} ; \mathrm{l})}{\mathrm{R}(\mathrm{n}+\mathrm{m} ; \mathrm{l})}=\mathrm{A} \neq 1$, A finite, then $\mathrm{T}_{+\mathrm{m}}$ $[\mathrm{S}(\mathrm{n}+\mathrm{m})]$ converges with the same order of rapidity as $\mathrm{S}(\mathrm{n}+\mathrm{m})$.

Proof: By Lemma $3.8 R(n ; 1) \rightarrow 0$ as $n \rightarrow \infty$ and thus $R(n ; m) \rightarrow 0$ as $n \rightarrow \infty$. It follows by Lemma 3.10 that $\lim _{n \rightarrow \infty} \frac{S(n+m)-S(n)}{a(n+1)}=1$ and the rest of the proof follows as in Theorem 3.9 except that in this case

$$
\lim _{n \rightarrow \infty} \frac{S-T_{+m}[S(n+m)]}{S-S(n+m)}=1-A \neq 0 .
$$


Theorem 3.12: If $\mathrm{a}(\mathrm{n})=(-1)^{\mathrm{n}} \mathrm{C}(\mathrm{n}), \mathrm{C}(\mathrm{n})>\mathrm{C}(\mathrm{n}+1)>0$, and

$$
\lim _{\mathrm{n} \rightarrow \infty} \frac{\mathrm{R}(\mathrm{n} ; \mathrm{l})}{\mathrm{R}(\mathrm{n}+\mathrm{m} ; \mathrm{l})}=\mathrm{A} \neq 1, \text { A finite, }
$$

then $\mathrm{T}_{+\mathrm{m}}[\mathrm{S}(\mathrm{n}+\mathrm{m})]$ converges with the same order of rapidity as $\mathrm{S}(\mathrm{n}+\mathrm{m})$.

Proof: The proof is much the same as the previous theorem.

THEOREM 3.13: If $\mathrm{a}(\mathrm{n})$ is of constant sign and $\lim _{\mathrm{n} \rightarrow \infty} \frac{\mathrm{R}(\mathrm{n} ; \mathrm{l})}{\mathrm{R}(\mathrm{n}+\mathrm{m} ; \mathrm{l})}=\infty$, then $\mathrm{S}(\mathrm{n}+\mathrm{m})$ converges more rapidly than $\mathrm{T}_{+\mathrm{m}}[\mathrm{S}(\mathrm{n}+\mathrm{m})]$.

Proof: The proof follows in the same manner as Theorem 3.9.

Theorem 3.14: If $\mathrm{a}(\mathrm{n})=(-1)^{\mathrm{n}} \mathrm{C}(\mathrm{n}), \mathrm{C}(\mathrm{n})>\mathrm{C}(\mathrm{n}+1)>0$ and $\frac{\mathrm{R}(\mathrm{n} ; \mathrm{l})}{\mathrm{R}(\mathrm{n}+\mathrm{m} ; \mathrm{l})} \rightarrow \infty$ as $\mathrm{n} \rightarrow \infty$, then $\mathrm{S}(\mathrm{n}+\mathrm{m})$ converges more rapidly than $\mathrm{T}_{+\mathrm{m}}[\mathrm{S}(\mathrm{n}+\mathrm{m})]$.

COROLlaRY 3.5: If $|\mathrm{a}(\mathrm{n})|$ is monotone decreasing or $\mathrm{a}(\mathrm{n})$ is of constant sign and if $\left|\mathrm{R}_{\mathrm{n}}\right| \neq 1$ and $\lim _{\mathrm{n} \rightarrow \infty} \frac{\mathrm{R}(\mathrm{n} ; \mathrm{l})}{\mathrm{R}(\mathrm{n}+\mathrm{m} ; \mathrm{l})}$ exists finite or infinite, then a necessary and sufficient condition that $\mathrm{T}_{+\mathrm{m}}[\mathrm{S}(\mathrm{n}+\mathrm{m})]$ converge more rapidly than $\mathrm{S}(\mathrm{n}+\mathrm{m})$ is that $\lim _{\mathrm{n} \rightarrow \infty} \frac{\mathrm{R}(\mathrm{n} ; \mathrm{l})}{\mathrm{R}(\mathrm{n}+\mathrm{m} ; 1)}=1$.

In the above theorems we have established a number of conditions under which $T_{+m}[S(n+m)]$ will converge more rapidly than $S(n+m)$. In general we have seen that it is desirable to select $m$, if possible, so that $\left|R_{m}\right|<1$, where $R_{m}=\lim _{n \rightarrow \infty} R(n ; m)$. Thus one should try to select $m$ so that $|a(n+m)|<|a(n)|$ for $n$ sufficiently large ${ }^{n \rightarrow \infty}$ and $R_{m}$ exists. Of course this will not guarantee that $\left|R_{m}\right|<1$, but if $m$ is not chosen in this manner there is no chance that $\left|R_{m}\right|<1$. In fact, by Lemma 3.3 if $R_{m}$ exists and $m$ cannot be chosen so that $|a(n+m)|<|a(n)|$ for $n$ sufficiently large, then $\left|R_{m}\right|=1$.

Before leaving the $T_{+m}$ transformation let us consider one more point. Initially we obtained this transformation by determining $g$ in the $T$ transformation so that $T$ was exact on geometric series. A question which naturally arises is whether $T_{+m}$ is exact on any other kind of series. The answer is effectively in the negative as the next theorem shows.

THEOREM 3.15: $\mathrm{T}_{+\mathrm{m}}$ is exact on $\mathrm{S}(\mathrm{n}+\mathrm{m})$ if and only if

$$
\sum_{n=N}^{\infty} a(n) \equiv \sum_{p=N}^{N+m-1} \sum_{k=0}^{\infty} a(p) \propto k
$$

for some $\mathrm{N}$, where $\propto$ is a constant such that $|\propto|<1$.

Proof: Since

$$
S-T_{+m}[S(n+m)]=\frac{1}{1-R(n ; m)}[S-S(n+m)]-R(n ; m)[S-S(n)],
$$

it is clear that $T_{+m}[S(n+m)] \equiv S$ for $n$ sufficiently large if and only if there exists an $N$ such that

$$
\frac{S-S(n+m)}{S-S(n)} \equiv R(n ; m)
$$

for $n \geqslant N$. But (3.75) is true if and only if $R(n ; m)=\propto, \propto a$ constant, when $n \geqslant N$. To see the latter note that if $R(n ; m)=\propto$ when $n \geqslant N$, then

$$
\frac{S-S(n+m)}{S-S(n)}=\frac{\sum_{j=n+1}^{\infty} a(j+m)}{\sum_{j=n+1}^{\infty} a(j)}=\propto \frac{\sum_{j=n+1}^{\infty} a(j)}{\sum_{j=n+1}^{\infty} a(j)}=\propto=R(n ; m)
$$

On the other hand if $T_{+m}$ is exact on $S(n+m)$, then

$$
S(n+m)-S=R(n ; m)[S(n)-S] \text { for } n \geqslant N .
$$


Thus

$[S(n+m+1)-S]-[S(n+m)-S]=R(n+1 ; m)[S(n+1)-S]-R(n ; m)[S(n)-S]$.

Hence

$$
\begin{aligned}
a(n+m+1)= & -S[R(n+1 ; m)-R(n ; m)]+[R(n+1 ; m)-R(n ; m)] S(n) \\
& +R(n+1 ; m)[S(n+1)-S(n)] \\
= & {[R(n+1 ; m)-R(n ; m)][S(n)-S]+a(n+m+1) . }
\end{aligned}
$$

Therefore,

$$
S=S(n) \text { or } R(n+1 ; m)=R(n ; m) \text { when } n \geqslant N .
$$

The former is false and consequently $R(n ; m)=\propto$ if $n \geqslant N$. Now since $R(n, m)$ is constant when $n \geqslant N$ and $S(n)$ converges, then $|\propto|<1$ and $T_{+m}$ exact implies for $k=1,2, \ldots$ that

$$
\begin{gathered}
a(n) \propto k=a(n+k m) \\
a(n+1) \propto k=a(n+k m+1) \\
\cdot \\
a(n+m-1) \propto k=a(n+k m+m-1),
\end{gathered}
$$

and therefore $T_{+m}$ exact implies that

$$
\begin{aligned}
\sum_{n=N}^{\infty} a(n) & =[a(N)+a(N+1)+\ldots+a(N+m-1)] \sum_{k=0}^{\infty} \propto k \\
& =\sum_{p=N}^{N+m-1} \sum_{k=0}^{\infty} a(p) \propto k
\end{aligned}
$$

and the necessity is proved.

The sufficiency easily follows since $\Sigma \propto k$ is a geometric series.

\section{The $\boldsymbol{T} \cdot m$ Transformation}

In the previous section we considered a transformation which we called the $T_{+m}$ transformation. In particular we found the transformation to be quite effective in increasing the rate of convergence of a series except when $R_{1}=1$. Thus if

$$
S(n)=\sum_{k=1}^{n} \frac{1}{k^{p}}, \quad p>1
$$

we would not be surprised to find that $T_{+m}[S(n+m)]$ does not converge more rapidly than $S(n+m)$ since

$$
R_{1}^{m}=\lim _{n \rightarrow \infty} \frac{a(n+m)}{a(n)}=\lim _{n \rightarrow \infty} \frac{n}{(n+m)}=1
$$

for every $m$.

In searching for a transformation which will be effective when $R_{1}=1$ we return to the $T$ transformation and recall that $T_{+m}$ was obtained by requiring $T$ to be exact on geometric series. Thus we might obtain a transformation which is more effective on series such as (4.1) if we require $T$ to be exact on a series which more closely resembles (4.1) than a geometric series. These considerations lead us to the following theorem. 
THEOREM 4.1: If $\mathrm{a}(\mathrm{n})=(\mathrm{n}-1)^{(-\mathrm{x})}$, then a necessary and sufficient condition for $\mathrm{T}$ to be exact is that $\mathrm{g}(\mathrm{n})=\frac{\mathrm{n}}{\propto}$, where $\frac{\mathrm{n}}{\propto}$ is a positive integer and $\propto \neq 1$. Before proving the theorem we should point out that the symbol $\mathrm{n}^{(-\mathrm{r})}$ denotes the fractorial function, i.e.

$$
n^{(-r)}=\frac{1}{(n+1)(n+2) \ldots(n+r)}, r \geqslant 1 .
$$

Thus

$$
(n-1)^{(-x)}=\frac{1}{n(n+1) \ldots(n+x-1)} .
$$

We will now proceed with the proof of Theorem 4.1.

Proof: As in Theorem 3.1, the result will follow if and only if

$$
-\sum_{k=n+1}^{\infty} a(k)+R(n, g(n)) \sum_{k=g(n)+1}^{\infty} a(k) \equiv 0
$$

when $n$ is sufficiently large.

But (4.5) can be written

$$
\frac{1}{x-1} n^{(-x+1)}-R(n, g(n))(g(n))^{(-x+1)} \equiv 0 .
$$

The latter implies that

$$
g(n+1)-g(n)=\frac{g(n)}{n},
$$

and hence

$$
g(n)=\frac{n}{\propto},
$$

where $\propto \neq 1$ is any constant such that $\frac{n}{\propto}$ is a positive integer. The above theorem leads us to the following definition.

Definition 4.1. Let $m$ be a positive integer such that $m>1$. Then we define the $T \cdot m$ transformation by

$$
\begin{aligned}
T_{\cdot m}[S(n m)] & =T[S(n m) ; n] \\
& =\frac{S(n m)-R(n m, n) S(n)}{1-R(n m, n)} .
\end{aligned}
$$

As in $T_{+m}$, for convenience, we will adopt a slightly different notation for $R(n m, n)$ in this special case. Thus we will let $R(n m, n)=\rho(n ; m)$. This notation will be convenient and save confusion with $R(n ; m)$ of section 3 . Thus

$$
T \cdot m[S(n m)]=\frac{S(n m)-\rho(n ; m) S(n)}{1-\rho(n ; m)},
$$

where

$$
\rho(n ; m)=\frac{m a(n m)}{a(n)} .
$$

Some alternate forms for (4.9) are the following:

$$
\begin{aligned}
& T \cdot m[S(n m)]=S(n)+\frac{S(n m)-S(n)}{1-\rho(n ; m)} \\
& T \cdot m[S(n m)]=\frac{m S(n) S(n m-1)-S(n-1) S(n m)-(m-1) S(n) S(n m)}{S(n)-S(n-1)-m[S(n m)-S(n m-1)]} .
\end{aligned}
$$


THEOREM 4.2: If there exists an $\mathrm{n}$ and an $\mathrm{M}$ such that $|1-\rho(\mathrm{n}, \mathrm{m})| \geqslant \mathrm{M}>0$ for $\mathrm{n}$ sufficiently large, then $\mathrm{T} \cdot \mathrm{m}[\mathrm{S}(\mathrm{nm})]$ converges to $\mathrm{S}$.

Proof: The result is a special case of Theorem 2.1.

Corollary 4.1: For every $\mathrm{m}$ such that $\lim _{\mathrm{n} \rightarrow \infty} \rho(\mathrm{n} ; \mathrm{m})=\rho_{\mathrm{m}} \neq 1, \mathrm{~T} \cdot \mathrm{m}[\mathrm{S}(\mathrm{nm})]$ converges to $\mathrm{S}$. In the future the symbol $\rho_{\mathrm{m}}$ will always refer to $\lim _{\mathrm{n} \rightarrow \infty} \rho(\mathrm{n} ; \mathrm{m})$.

LEMMA 4.1: If $\mathrm{a}(\mathrm{n})=0\left(\mathrm{n}^{-\infty}\right)$ as $\mathrm{n} \rightarrow \infty$ and $\propto>1$, then

$$
\lim _{n \rightarrow \infty}(\log n)(S(n m)-S(n))=0 .
$$

Proof: There exists $m$ and $N$ such that for $n \geqslant N$

$$
\begin{aligned}
\mid(\log n)[S(n m) & -S(n)] \mid \leqslant(\log n)(|a(n+1)|+|a(n+2)|+\ldots+|a(n m)|) \\
& \leqslant(\log n) M\left[(n+1)^{-\propto}+(n+2)^{-\alpha}+\ldots+(n m)^{-\alpha}\right] \\
& \leqslant(\log n) M n(m-1)(n+1)^{-\propto+1} \\
& \leqslant M(\log n)(m-1)(n+1)^{-\alpha+1} .
\end{aligned}
$$

But $\propto>1$ and $(\log n)(n+1)^{-\infty+1}$ converges to zero as $n \rightarrow \infty$. Thus the lemma follows.

THEOREM 4.3: If $\mathrm{a}(\mathrm{n})=0\left(\mathrm{n}^{-\alpha_{1}}\right), \propto>1$, then for every $\mathrm{m}$ such that $\mathrm{T} \cdot \mathrm{m}[\mathrm{S}(\mathrm{nm})]$ converges as $\mathrm{n} \rightarrow \infty$ we have

$$
\lim _{n \rightarrow \infty} T \cdot m[S(n m)]=\lim _{n \rightarrow \infty} S(n)=S .
$$

Proof: Let $m$ be any integer such that $m>1$ and $T \cdot m$ converges to $L_{m}$ and assume that

$$
T \cdot m[S(n m)]-S(n)=\frac{S(m n)-S(n)}{1-\rho(n ; m)} \rightarrow L_{m}-S \neq 0
$$

as $n \rightarrow \infty$. By Lemma $4.3(\log n)(S(m n)-S(n)) \rightarrow 0$ as $n \rightarrow \infty$. Thus, from $(4.15),(\log n)(1-\rho(n ; m))$ $\rightarrow 0$ as $n \rightarrow \infty$. Now let $n=m^{p}, p=0,1,2,3, \ldots$ Then $\log n=p \log m$ and consequently $p \rightarrow \infty$ if and only if $n \rightarrow \infty$. Therefore

$$
\lim _{p \rightarrow \infty} p\left[1-\rho\left(m^{p} ; m\right)\right]=0,
$$

where

$$
\rho\left(m^{p} ; m\right)=\frac{m a\left(m^{p+1}\right)}{a\left(m^{p}\right)} .
$$

Now if we let $b(p)=m^{p} a\left(m^{p}\right)$ we have

$$
\rho\left(m^{p} ; m\right)=\frac{b(p+1)}{b(p)} .
$$

Now $b(p+1) / b(p)$ is eventually positive since $\lim _{p \rightarrow \infty} \rho\left(m^{p} ; m\right)=1$.

Thus

$$
\lim _{p \rightarrow \infty} p\left[1-\frac{b(p+1)}{b(p)}\right]=0
$$

and by Raabe's Test the series

$$
\sum_{p=0}^{\infty} b(p)
$$


diverges. But, for $n$ sufficiently large,

However,

$$
\begin{gathered}
|b(p)|=\left|m^{p} a\left(m^{p}\right)\right| \leqslant m^{p} M\left(m^{p}\right)^{-\propto} \\
=M\left(m^{1-\propto}\right)^{p} . \\
M \sum_{p=1}^{\infty}\left(m^{1-\alpha}\right)^{p}
\end{gathered}
$$

converges when $m$ and $\propto>1$. Thus (4.20) converges absolutely. This is a contradiction and the theorem follows.

An interesting class of functions for which $T_{. m}$ will be useful is considered in the following theorem. For these functions one would expect $T_{. m}$ to be more effective than $T_{+m}$. This latter statement can be easily verified by investigating $R(n ; m)$ and $\rho(n ; m)$. That is, by noting that $\lim _{n \rightarrow \infty} R(n ; m)=1$ and $\lim _{n \rightarrow \infty} \rho(n ; m) \neq 1,0$ for the class of functions discussed in the following theorem.

THeORem 4.4: If $\mathrm{a}(\mathrm{n})=\frac{\mathrm{u}(\mathrm{n})}{\mathrm{v}(\mathrm{n})}$, where $\mathrm{u}(\mathrm{n})=\sum_{\mathrm{i}=0}^{\mathrm{N}} \mathrm{C}_{\mathrm{i}} \mathrm{n}^{\mathrm{r}-\mathrm{i}}, \mathrm{v}(\mathrm{n})=\sum_{\mathrm{i}=0}^{\mathrm{M}} \mathrm{d}_{\mathrm{i}} \mathrm{n}^{\mathrm{s}-\mathrm{i}}, \mathrm{r} \geqslant \mathrm{N}, \mathrm{S} \geqslant \mathrm{M}, \mathrm{S}>\mathrm{r}+1$ and $\mathrm{C}_{\mathrm{o}} \mathrm{d}_{0} \neq 0$, then $\mathrm{T}_{\text {. } \mathrm{m}}[\mathrm{S}(\mathrm{nm})]$ converges to $\mathrm{S}$, i.e.,

ProOF:

$$
\lim _{n \rightarrow \infty} T_{. m}[S(n m)]=\sum_{n=1}^{\infty} a(n) .
$$

$$
\frac{m a(m n)}{a(n)}=\frac{m \sum_{i=0}^{N} C_{i}(n m)^{r-i}}{\sum_{i=0}^{M} d_{i}(n m)^{s-i}} \cdot \frac{\sum_{i=0}^{M} d_{i} n^{s-i}}{\sum_{i=0}^{N} C_{i} n^{r-i}} .
$$

Thus

$$
\lim _{n \rightarrow \infty} \rho(n ; m)=m^{r-s+1} \neq 1
$$

and Corollary 4.1 applies.

THEOREM 4.5: If $\rho_{\mathrm{m}} \neq 0,1$, then $\mathrm{T}_{\mathrm{m}}[\mathrm{S}(\mathrm{mn})]$ converges more rapidly than $\mathrm{S}(\mathrm{nm})$ if and only if

$$
\lim _{n \rightarrow \infty} \frac{S-S(n m)}{S-S(n)}=\rho_{m}
$$

Proof: The theorem is a special case of Theorem 2.2.

Before we proceed further let us recall that $T_{. m}$ was initially considered to circumvent the problem of $R_{m}=1$ in $T_{+m}$. Consequently, a question which naturally arises and which is of some importance is the following: Is the class of sequences in Theorem 4.5 distinct from the class of sequences in Theorem 3.8? That is, we know that if $R_{m} \neq 0,1$, then a necessary and sufficient condition for $T_{+m}$ to induce more rapid convergence on a sequence is that

$$
R_{m}=\lim _{n \rightarrow \infty}\left[\frac{(S-S(n+m))}{(S-S(n))}\right] .
$$

But by Theorem 4.5T.m will also induce more rapid convergence if (4.25) holds. Thus, do there exist sequences for which both Theorem 4.5 and Theorem 3.8 apply and if so which transformation would be preferable? The dilemma is effectively resolved by the following theorem.

Theorem 4.6: If $\lim \mathrm{R}(\mathrm{n}, 1)=\mathrm{R}_{1}, 0<\left|\mathrm{R}_{1}\right|<1$ and $\rho_{\mathrm{m}}$ exists, then $\rho_{\mathrm{m}}=0$.

Proof: Suppose $\rho_{m} \neq 0$, then we have

$$
\begin{aligned}
R_{1} & =\lim _{n \rightarrow \infty} \frac{a(n m+1)}{a(n m)} \\
& =\lim _{n \rightarrow \infty}\left[\frac{a(n m+1)}{a(n m+2)} \cdot \frac{a(n m+2)}{a(n m+3)} \cdots \frac{a(m n+m-1)}{a(n m+m)} \cdot \frac{a(n m+m)}{a(n+1)} \cdot \frac{a(n+1)}{a(n)} \cdot \frac{a(n)}{a(n m)}\right]
\end{aligned}
$$




$$
=\frac{1}{R_{1}} \cdot \frac{1}{R_{1}} \cdot \cdot \frac{1}{R_{1}} \cdot \frac{\rho_{m}}{M} \cdot R_{1} \cdot \frac{M}{\rho_{m}}=\frac{1}{R_{1}^{m-2}} .
$$

Thus $R_{1}^{m-1}=1$ and, since $m \geqslant 2,|R|=1$. The theorem therefore follows. We see therefore that with the exception of $R_{1}=-1$ the two theorems refer to disjoint sets of sequences. Note that in the event $m=2 k$ that $R_{m}=1$ and in that case the two theorems refer to two distinct classes of sequences without exception. That is, if $T_{. m}$ induces more rapid convergence by Theorem 4.5 , then Theorem 3.8 does not apply since we must have $R_{m}=1$ by Theorem 4.6.

LEMMA 4.2: If $\mathrm{R}_{1}=0$, then $\rho_{m}=0$.

Proof: If $\epsilon>0$, then there exists an integer $N$ such that if $n \geqslant N|R(n ; 1)|<1$ and $|R(n ; 1)|<\epsilon$. Thus $|a(n+1)|<|a(n)|$ and $|a(n+1)|<\epsilon|a(n)|$. Since $n m \geqslant n+1$, it follows that $|a(n m)|<\mid$ $a(n+1)|<| a(n+1)<|a(n)|$. Hence, $\left|\frac{a(n m)}{a(n)}\right|<\epsilon$ and the lemma follows.

LEMMA 4.3: If $\mathrm{R}_{1} \neq-1$ and $\rho_{m}$ exists, then $\frac{\mathrm{ma}(\mathrm{nm}+\mathrm{p})}{\mathrm{a}(\mathrm{n}+1)} \rightarrow \rho_{m}$ as $\mathrm{n} \rightarrow \infty$ for each integer $\mathrm{p} \geqslant 0$. Moreover, if $\mathrm{R}=-1$, then $\frac{\mathrm{ma}(\mathrm{nm}+\mathrm{p})}{\mathrm{a}(\mathrm{n}+1)} \rightarrow(-1)^{p+1} \rho_{m}$ as $\mathrm{n} \rightarrow \infty$.

Proof: If $\left|R_{1}\right|<1$, then, by Theorem 4.6 and Lemma 4.2, $\rho_{m}=0$. Also, as in Lemma 4.2, $|a(n m+p)<| a(n+2)|<\epsilon| a(n+1) \mid$. Thus $\frac{m a(n m+p)}{a(n+1)} \rightarrow 0=\rho_{m}$. Consideration of the expression

$$
\frac{a(n m+p)}{a(n+1)}=\frac{a(n m)}{a(n)} \cdot \frac{a(n m+1)}{a(n m)} \ldots \frac{a(n k+p)}{a(n k+p-1)} \cdot \frac{a(n)}{a(n+1)}
$$

yields the required result for $\left|R_{1}\right|=1$.

TheOREM 4.7: If $\mathrm{S}(\mathrm{n})$ is monotone, $\mathrm{R}(\mathrm{n}, \mathrm{l}) \rightarrow \mathrm{R}$ and $\rho_{\mathrm{m}}$ exists, then $\frac{\mathrm{S}-\mathrm{S}(\mathrm{mn})}{\mathrm{S}-\mathrm{S}(\mathrm{p})} \rightarrow \rho_{\mathrm{m}}$ as $\mathrm{n} \rightarrow \infty$.

Proof: $S(n)$ being monotone implies that $R_{1} \neq-1$. Also

$$
\frac{S(m n)-S(m n-m)}{S(n)-S(n-1)}=\frac{a[(n-1) m+1]}{a(n)}+\ldots+\frac{a[(n-1) m+m]}{a(n)} .
$$

By lemma 4.3, this converges to $\rho_{m}$. Thus, by Theorem $3.2, \frac{S-S(m n)}{S-S(n)} \rightarrow \rho_{m}$.

THEOREM 4.8: If $\mathrm{S}(\mathrm{n})$ is monotone, $\mathrm{R}(\mathrm{n} ; 1)$ converges and $\rho_{\mathrm{m}} \neq 0,1$, then $\mathrm{T}_{\mathrm{m}}$ converges more rapidly than $\mathrm{S}(\mathrm{nm})$.

Proof: In this case $\frac{\mathrm{S}-\mathrm{S}(\mathrm{nm})}{\mathrm{S}-\mathrm{S}(\mathrm{n})} \rightarrow \rho_{m}$ and Theorem 4.5 applies.

THEOREM 4.9: If $\mathrm{a}(\mathrm{n})$ is of constant sign and satisfies the conditions of Theorem 4.4, then $\mathrm{T}_{. m}$ converges to $\mathrm{S}$ more rapidly than $\mathrm{S}(\mathrm{mn})$.

Proof: $R n ; 1) \rightarrow 1$ and $\rho_{m}=m^{r-s+1} \neq 0,1$. Thes Theorem 4.8 applies.

The following examples illustrate the advantage of $T_{. m}$ over $T_{+m}$ when $R_{m}=1$.

ExAmPle 4.1: Let $S(n)=\frac{n}{n+1}$. Then

(i) $S=1$

(ii) $a(n)=\frac{1}{n(\overline{n+1)}}$

(iii) $R_{m}=1$ and $\rho_{m}=\frac{1}{m}$ 
(iv) $T_{+m}[S(n+m)]=\frac{2 n+m}{2 n+m+1}$

(v) $T \cdot m[S(n m)]=1$.

Obviously, $T_{+m}$ and $S(n+m)$ converge at the same rate while $T_{\cdot m}$ is exact and converges more rapidly than $S(n m)$ and $S(n+m)$.

Let

EXAMPLE 4.2: The transforms considered are $T_{+1}$ and $T_{.2}$.

$$
S=\frac{(1+1)+1}{1+1}+\frac{2^{4}+2^{2}+1}{2^{2}\left(2^{4}+1\right)}+\frac{3^{4}+3^{2}+1}{3^{2}\left(3^{4}+1\right)}+\ldots
$$

Then $a_{n}=\frac{n^{4}+n^{2}+1}{n^{2}\left(n^{4}+1\right)}$ and $R_{1}=1, \rho_{m}=1 / 2$.

Since $a_{n}>0, \rho_{m} \neq 0,1$ and $R(n ; 1)$ converges, it follows that $T_{{ }_{2}}$ converges more rapidly to $S$ than $S(2 n)$. However, this example is given by Lubkin [11] to show that $T_{+1}$ diverges!

EXAMPLE 4.3: The transforms considered are $T_{+1}$ and $T_{.2}$. Let $S_{n}=\sum_{k=1}^{n} \frac{1}{k^{2}}$. Then $S_{n} \rightarrow \Pi^{2} / 6$. The transforms were applied in the forms

and

$$
T_{+1}[S(n+1)]=\frac{S(n+1) S(n-1)-[S(n)]^{2}}{S(n+1)+S(n-1)-2 S(n)}
$$

$$
T_{\cdot 2}[S(2 n)]=\frac{2 S(n) S(2 n-1)-S(n-1) S(2 n)-S(n) S(2 n)}{S(n)-S(n-1)-2[S(2 n)-S(2 n-1)]}
$$

for computational ease.

$S(1)$ through $S(10)$ was the only information used. The transforms were then reapplied to the resulting sequences. The process was repeated to get the final results.

\begin{tabular}{|c|c|c|c|}
\hline$n$ & $S_{n}$ & $T_{\cdot 2}[S(2 n)]$ & Error \\
\hline $\begin{array}{r}1 \\
2 \\
3 \\
4 \\
5 \\
6 \\
7 \\
8 \\
9 \\
10\end{array}$ & $\begin{array}{lll}1.000 & 000 & 0 \\
1.250 & 000 & 0 \\
1.361 & 111 & 1 \\
1.423 & 611 & 1 \\
1.463 & 611 & 1 \\
1.491 & 388 & 3 \\
1.511 & 796 & 9 \\
1.527 & 421 & 9 \\
1.539 & 767 & 5 \\
1.549 & 767 & 5\end{array}$ & $\begin{array}{rrrrr}0.159 & 722 & 2 & \mathrm{D} & 01 \\
.162 & 166 & 7 & \mathrm{D} & 01 \\
.163 & 123 & 3 & \mathrm{D} & 01 \\
.163 & 592 & 4 & \mathrm{D} & 01\end{array}$ & 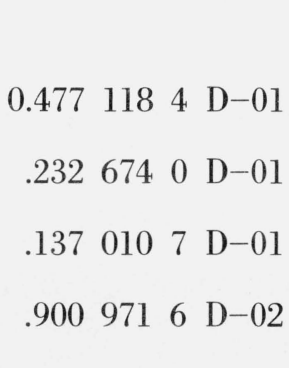 \\
\hline
\end{tabular}

The process is illustrated in the following tabular form. The symbols $T_{+1}^{n}$ and $T_{{ }^{n} 2}^{n}$ refer to $n$ applications of the respective transforms.

\begin{tabular}{|c|c|}
\hline$T_{\cdot 2}^{2}[S(2 n)]$ & Error \\
\hline $0.1644806 \mathrm{D} 01$ & $0.1278793 \mathrm{D}-03$ \\
\hline
\end{tabular}

The notation D 01 above indicates the position of the decimal. Thus $0.1278793 \mathrm{D}-03$ is 0.0001278793 . 


\begin{tabular}{|c|c|c|c|}
\hline$n$ & $S_{n}$ & $T_{+1}[S(n+1)]$ & Error \\
\hline $\begin{array}{r}1 \\
2 \\
3 \\
4 \\
5 \\
6 \\
7 \\
8 \\
9 \\
10\end{array}$ & $\begin{array}{l}1.0000000 \\
1.2500000 \\
1.3611111 \\
1.4236111 \\
1.4636111 \\
1.4913888 \\
1.5117969 \\
1.5274219 \\
1.5397675 \\
1.5497675\end{array}$ & $\begin{array}{rrrrr}0.145 & 000 & 0 & \mathrm{D} & 01 \\
.150 & 396 & 8 & \mathrm{D} & 01 \\
.153 & 472 & 2 & \mathrm{D} & 01 \\
.155 & 452 & 0 & \mathrm{D} & 01 \\
.156 & 831 & 2 & \mathrm{D} & 01 \\
.157 & 846 & 4 & \mathrm{D} & 01 \\
.158 & 624 & 6 & \mathrm{D} & 01 \\
.159 & 239 & 9 & \mathrm{D} & 01\end{array}$ & $\begin{array}{rrrr}0.194 & 934 & 1 & \mathrm{D}-00 \\
.140 & 965 & 8 & \mathrm{D}-00 \\
.110 & 211 & 8 & \mathrm{D}-00 \\
.904 & 138 & 6 & \mathrm{D}-01 \\
.776 & 221 & 0 & \mathrm{D}-01 \\
.664 & 703 & 5 & \mathrm{D}-01 \\
.586 & 884 & 9 & \mathrm{D}-01 \\
.525 & 347 & 6 & \mathrm{D}-01\end{array}$ \\
\hline
\end{tabular}

\begin{tabular}{|c|c|}
\hline$T_{+1}^{2}[S(n+1)]$ & Error \\
\hline $1.157 \begin{array}{llllll}546 & 465 & 879 & 801 & \text { D } & 01\end{array}$ & $\begin{array}{llllll}0.694 & 694 & 080 & 502 & 174 & \mathrm{D}-01\end{array}$ \\
\hline $\begin{array}{lllllll}0.159 & 029 & 607 & 068 & 481 & \mathrm{D} & 01\end{array}$ & 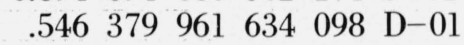 \\
\hline $\begin{array}{lllllll}.159 & 998 & 128 & 111 & 844 & \text { D } & 01\end{array}$ & $\begin{array}{llllll}4449 & 527 & 857 & 297 & 853 & \mathrm{D}-01\end{array}$ \\
\hline $.160677629679 \quad 179 \quad \mathrm{D} \quad 01$ & $\begin{array}{llllll}.381 & 577 & 700 & 564 & 282 & \mathrm{D}-01\end{array}$ \\
\hline $.161 \quad 179840516212 \quad \mathrm{D} 01$ & $\begin{array}{llllll}.331 & 356 & 616 & 861 & 027 & \mathrm{D}-01\end{array}$ \\
\hline $\begin{array}{lllllll}161 & 565 & 806 & 547 & 658 & \mathrm{D} & 01\end{array}$ & $\begin{array}{llllll}.292 & 760 & 013 & 716 & 415 & \mathrm{D}-01\end{array}$ \\
\hline
\end{tabular}

\begin{tabular}{|c|c|}
\hline$T_{+1}^{3}[S(n+1)]$ & Error \\
\hline $\begin{array}{rrrrrrr}0.161 & 820 & 895 & 875 & 573 & \mathrm{D} & 01 \\
.162 & 275 & 177 & 312 & 803 & \mathrm{D} & 01 \\
.162 & 602 & 451 & 412 & 998 & \mathrm{D} & 01 \\
.162 & 847 & 324 & 260 & 966 & \mathrm{D} & 01\end{array}$ & $\begin{array}{rrrrrr}0.267 & 251 & 080 & 924 & 982 & \mathrm{D}-01 \\
.221 & 822 & 037 & 201 & 894 & \mathrm{D}-01 \\
.189 & 095 & 527 & 182 & 483 & \mathrm{D}-01 \\
.164 & 608 & 242 & 385 & 657 & \mathrm{D}-01\end{array}$ \\
\hline
\end{tabular}

\begin{tabular}{|c|c|}
\hline$\left.\left.T_{+1}^{3}[S) n+1\right)\right]$ & Error \\
\hline $\begin{array}{rrrrrrr}0.163 & 445 & 775 & 421 & 854 & \mathrm{D} & 01 \\
.163 & 575 & 016 & 014 & 021 & \mathrm{D} & 01\end{array}$ & $\begin{array}{rrrrrr}0.104 & 763 & 126 & 296 & 867 & \mathrm{D}-01 \\
.918 & 390 & 670 & 801 & 172 & \mathrm{D}-02\end{array}$ \\
\hline
\end{tabular}

In the above it should be noted that two applications of $T_{{ }_{2}}$ have yielded better results than four applications of $T_{+1}$ even though each application of $T_{+1}$ gave a better result than the previous application of $T_{+1}$. 


\section{References}

[1] Aitken, A. C., On Bernoulli's numerical solution of algebraic equations, Proc. Roy. Soc. Edinburgh 46, 289-305 (1926).

[2] Aitken, A. C., Studies in practical mathematics II, Proc. Roy. Soc. Edinburgh 5 7, 269-304 (1937).

[3] Bromwich, T. J., An Introduction To The Theory of Infinite Series, 2d ed. (Macmillan and Co. Ltd. New York, 1926).

[4] Clark, W. D., Infinite Series Transformations and Their Application Doctoral dissertation, University of Texas, Jan. 1968.

[5] Gray, H. L., and T. A. Atchison, Nonlinear transformations related to the evaluation of improper integrals I. SIAM J. Numer. Anal. 4, No. 3, 363-371 (1967).

[6] Gray, H. L., and Atchison, T. A., Nonlinear transformations related to the evaluation of improper integrals I. SIAM J. Numer. Anal. 4, No. 3, 363-371 (1967).

[7] Gray, H. L., and Atchison, T. A., The generalized G-transform, Math Comp. (To appear July 1968).

[8] Gray, H. L., and Atchison, T. A., A note on the G-transformation, J. Res. NBS 72B (Math. Sci.) No. 1, 25-29 (1968).

[9] Gray, H. L., and Schucany, W. R., On the evaluation of distribution functions, J. of the American Statistical Assoc. (To appear) June 1968.

[10] Gray, H. L., and Schucany, W. R., A new approximation related to the error function, Math. Comp. (Jan. 1968),

[11] Lubkin, Samuel, A method of summing infinite series, J. Res. NBS 48, 228-254 (1955) RP2310.

[12] Shanks, Daniel, Nonlinear transformations of divergent and slowly convergent sequences, J. Math Phys. 34, 1-42. (1955).

(Paper 73B3-306) 


\section{Publications of the National Bureau of Standards*}

\section{Other NBS Publications}

J. Res. Nat. Bur. Stand. (U.S.), 73A (Phys. and Chem.), No. 3 (May-June 1969), \$1.00.

New even levels and classified lines in the first spectrum of tungsten (W I). C. H. Corliss.

The heat of combustion of beryllium in fluorine. K. L. Churney, and G. T. Armstrong.

Deuterium istope effect on the dissociation of weak acids in water and deuterium oxide. R. A. Robinson, M. Paabo, and

R. G. Bates.

Vortex motions in ideal Bose superfluid. M. J. Cooper.

Franck-Condon factors for the ionization of $\mathrm{H}_{2} \mathrm{O}$ and $\mathrm{D}_{2} \mathrm{O}$. R. Botter and H. M. Rosenstock.

Topological features of hot carrier induced anisotropic breakdown on silicon diode surfaces. G. G. Harman.

The third spectrum of praseodymium (Pr III) in the vacuum ultraviolet. J. Sugar.

J. Res. Nat. Bur. Stand. (U.S.), 73A (Phys. and Chem.), No. 4 (July-AAug. 1969), \$1.00.

Classical path methods in line broadening. I. The classical path approximation. E. W. Smith, C. R. Vidal, and J. Cooper.

Classical path methods in line broadening. II. Application to the Lyman series of hydrogen. E. W. Smith, C. R. Vidal, and J. Cooper.

The second virial coefficient for the realistic pair potential. H. W. Woolley.

Synthesis of barium ferrates in oxygen. T. Negas and R. S. Roth.

The system SrO-"chromium oxide" in air and oxygen. T. Negas and R. S. Roth.

Anderson, G. B., Raybold, R. C., Studies of calibration procedures for load cells and proving rings as weighing devices, Tech. Note 436 (Jan. 1969), 30 cents.

Barnes, J. A., Tables of bias functions, $B_{1}$ and $B_{2}$, for variances based on finite samples of processes with power law spectral densities, Tech. Note 375 (Jan. 1969), 50 cents.

Bean, B. L., Dise, J. R., Causes of variation in chemical analysis and physical tests of portland cement, Nat. Bur. Stand. (U.S.), Bldg. Sci. Ser. 17, 32 pages (March 1969), 40 cents.

Beeghly, H. F., Cali, J. P., Meinke, W. W., Editors, Nuclear standards for chemistry and technology. Proceedings of a Symposium on Standards, in Nuclear Chemistry and Technology held at the 156th National Meeting of the American Chemical Society, Atlantic City, N.J., September 8-9, 1968, Nat. Bur. Stand. (U.S.), Spec. Publ. 310,261 pages (Dec. 1968), \$1.25.

Blaine, R. L., Arni, H. T., Evans, D. N., Interrelations between cement and concrete properties, Part 4, Shrinkage of neat portland cement pastes and concretes, Nat. Bur. Stand. (U.S.), Bldg. Sci. Ser. 15, 79 pages (March 1969 ), 75 cents.

Boone, T. H., Skoda, L. F., Cullen, W. C., Laboratory-field comparisons of built-up roofiing membranes, Tech. Note 473 (Dec. 1968), 25 cents.

Braun, W., Carrington, T., Line emission sources for concentration measurements and photochemistry, Nat. Bur. Stand. (U.S.), Tech. Note 476, 23 pages (March 1969), 30 cents.

Brief history and use of the English and metric systems of measurement with a chart of the modernized metric system, $1 / 3$ the dimensions of actual chart (SP 304), Spec. Publ. 304A (1968), 20 cents.

Bryson, J. O., Gross, D., Techniques for the survey and evaluation of live floor loads and fire loads in modern office buildings, Bldg. Sci. Series 16 (Dec. 1968), 40 cents.

Bullis, W. M., Editor, Methods of measurement for semiconductor materials, process control, and devices. Quarterly report July 1 to September 30, 1968, Tech. Note 472 (Dec. 1968), 50 cents.

Bullis, W. M., Editor, Methods of measurement for semiconductor materials, process control, and devices. Quarterly report October 1 to December 31, 1968, Tech. Note 475 (Feb. 1969), 45 cents.

DeVoe, J. R., Editor, Radiochemical Analysis Section: Summary of activities July 1967 to June 1968, Tech. Note 451 (Jan. 1969), $\$ 1.25$.

Diamond, J. J., Editor, Bibliography on the high temperature chemistry and physics of materials. October, November, December 1968, Spec. Publ. 315 (Jan. 1969), 70 cents.

Edmonds, D. K., Hord, J., Incipient and developed cavitation in liquid cryogens, Tech. Note 374 (Feb. 1969), 35 cents.

Freeman, D. H., Editor, Separation and Purification Section: Summary of activities July 1967 to June 1968, Tech. Note 459 (Dec. 1968), 60 cents.

Gebbie, K. B., Thomas, R. N., Editors, Wolf-Rayet stars, Proc. Symp. held at Joint Institute for Laboratory Astrophysics, University of Colorado, Boulder, Colorado, June 10-14, 1968, Spec. Publ. 307 (Dec. 1968), \$3.00.

Gosman, A. L., McCarty, R. D., Hust, J. G., Thermodynamic properties of argon from the triple point to $300 \mathrm{~K}$ at pressures to 1000 atmospheres, Nat. Bur. Stand. (U.S.), Nat. Stand. Ref. Data Ser. 27, 153 pages (March 1969), \$1.25.

Greenfeld, S. H., The performance of roofing made with asplund felts, Nat. Bur. Stand. (U.S.), Tech. Note 477,27 pages (March 1969), 35 cents.

Gross, D., Loftus, J. J., Lee, T. G., Gray, V. E., Smoke and gases produced by burning aircraft interior materials, Bldg. Sci. Series 18 (Feb. 1969), 35 cents.

Hermach, F. L., Dziuba, R. F., Precision measurement and calibration. Selected NBS papers on electricity-low frequency, Spec. Publ. 300, Vol. 3 (Dec. 1968), \$4.50. (Supersedes in part Handbook 77, Vol. I).

$\mathrm{Ku}$, H. H., Editor, Precision measurement and calibration. Statistical concepts and procedures, Nat. Bur. Stand. (U.S.), Spec. Publ. 300, Volume I, 436 pages (Feb. 1969), \$5.50.

LaFleur, P. D., Editor, Activation Analysis Section: Summary of activities July 1967 to June 1968, Nat. Bur. Stand. (U.S.), Tech. Note 458, 109 pages (March 1969), \$1.00.

Messina, C. G., Hilsenrath, J., Edpac: Utility programs for computer-assisted editing, copy-production, and data retrieval, Tech. Note 470 (Jan. 1969), 75 cents. 
Miles, B. M., Wiese, W. L., Critically evaluated transition probabilities for Ba I and II, Tech. Note 474 (Jan. 1969$), 30$ cents.

Shields, W. R., Editor, Analytical Mass Spectrometry Section: Summary of activities July 1967 to June 1968, Tech. Note 456 (Nov. 1968), 55 cents.

The modernized metric system, the International System of units (SI) and its relationship to U.S. customary units, illustrated color wall chart 45 x 29 inches, Spec. Publ. 304 (1968), 50 cents. (Supersedes Misc. Publ. 232).

Wegstein, J. H., A semi-automated single fingerprint identification system, Nat. Bur. Stand. (U.S.), Tech. Note 481, 23 pages (Apr. 1969), 30 cents.

White, H. S., Jr., Editor, General description of the Federal Information Processing Standards Register, Fed. Info. Process. Std. Pub. (FIPS) 0 (Nov. 1, 1968), 20 cents.

White, H. S., Jr., Editor, Code for information interchange, Fed. Info. Process. Std. Pub. (FIPS) 1 (Nov. 1,1968$), 10$ cents.

White, H. S., Jr., Editor, Perforated tape code for information interchange, Fed. Info. Process. Std. Pub. (FIPS) 2 (Nov. 1, 1968), 10 cents.

White, H. S., Jr., Editor, Recorded magnetic tape for information interchange (800 CPI, NRZI), Fed. Info. Process. Std. Pub. (FIPS) 3 (Nov. 1, 1968), 10 cents.

White, H. S., Jr., Editor, Calendar date, Fed. Info. Process. Std. Pub. (FIPS) 4 (Nov. 1, 1968), 20 cents.

White, H. S., Jr., Editor, States of the United States, Fed. Info. Process. Std. Pub. (FIPS) 5 (Nov. 1, 1968 ), 20 cents.

White, H. S., Jr., Editor, Counties of the States of the United States, Fed. Info. Process. Std. Pub. (FIPS) 6 (Nov. 1, 1968), 40 cents.

Youden, W. W., Computer literature bibliography. Volume 2, 1964-1967, Spec. Publ. 309 (Dec. 1968), \$5.00.

Yakowitz, H., Michaelis, R. E., Vieth, D. L., Standard Reference Materials: Homogeneity characterization of NBS spectrometric standards IV: Preparation and microprobe characterization of W-20\% Mo alloy fabricated by powder metallurgical methods, Nat. Bur. Stand. (U.S.), Spec. Publ. 260-16, 30 pages (Jan. 1969), 35 cents.

Ambler, E., Schooley, J. F., Colwell, J. H., Pfeiffer, E. R., Frederikse, H. R., Hosler, W. R., Thurber, W. R., Transition temperatures and critical fields of $\mathrm{SrTiO}_{3}$ and mixed titanates, Proc. Xth Intern. Conf. Low Temperature Physics, Moscow, U.S.S.R., Aug. 31-Sept. 6, 1966, Vol. 2B, Superconductivity, Paper S123 142-148 (1968).

Barber, D. J., Tighe, N. J., Neutron damage in single crystal aluminum oxide, J. Am. Ceram. Soc. 51, No. 11, 611-617 (Nov. 1968).

Barger, R. L., Hall, J. L., Pressure shift and broadening of methane line at $3.39 \mu$ studied by laser-saturated molecular absorption, Phys. Rev. Letters 22, No. 1, 4-8 (Jan. 6, 1969).

Bates, R. G., Equilibrium properties of acids and bases in amphiprotic mixed solvents (Proc. Symp. Equilibria and Reaction Kinetics in Hydrogen Bonded Solvent Systems, University of New Castle Upon Tyne, England, Jan. 10-12, 1968), Chapter in Hydrogen-Bonded Solvent Systems, A. K. Covington and P. Jones, Ed., pp. 49-86 (Taylor and Francis, London, England, 1968).

Bay, Z., Luther, G. C., Locking a laser frequency to the time standard, Appl. Phys. Letters 13, No. 9, 303-304 (Nov. 1, 1968).

Beatty, R. W., Fentress, G. H., An attenuation and phase shift divider circuit, Proc. IEEE 56, No. 11, 2063-2064 (Nov. 1968).

Beckett, C. W., Cezairliyan, A., High-speed thermodynamic measurements and related techniques, chapt. in Book, Experimental Thermodynamics, Ed., J. P. McCullough and D. W. Scott, Vol. I, Calorimetry of Non-reacting Systems, chapt. 14, 551-585 (Butterworth and Co., London, England, 1968).

Bekkedahl, N., Crystallization of natural rubber, Rev. Gen. Caoutchouc Plastiques 45, No. 3, 341-6-463-9 (1968).

Bender, P. L., Alley, C. O., Currie, D. G., Faller, J. E., Satellite geodesy using laser range measurements only, J. Geophys. Res. 73, No. 16, 5353-5358 (Aug. 15, 1968).

Bennett, L. H., Nuclear magnetism, chapt. in Book, Magnetism and Magnetic Materials 1968 Digest, Ed. H. Chand and T. R. McGuire, chapt. 14, pp. 201-221 (Academic Press Inc., New York, N.Y., 1968).

Bennett, L. H., Swartzendruber, L. J., Some comments on The corrosion of materials in desalination plants, Desalination 4, 389-390 (1968).

Blandford, J. M., NBS-ARF apparel materials testing and evaluation project, Second Annual Conf. Apparel Research Foundation, Washington, D.C., Oct. 7-9, 1968, 4 pages (Apparel Research Foundation, Washington, D.C., 1968).

Botter, R., Rosenstock, H. M., Franck-Condon factors for $\mathrm{NH}_{3}$ and $\mathrm{H}_{2} \mathrm{O}$, chapter in Advances in Mass Spectrometry, 4, 579-589 (Institute of Petroleum, London, England, 1968).

Brinckman, F. E., Gordon, G., Energetic intermediates in inorganic synthesis: characterization of transport species in electric discharge, Proc. Intern. Symp. Decomposition of Organometallic Compounds to Refractory Ceramics, Metals, and Metal Alloys, Dayton, Ohio, Nov. 1967, pp. 29-46 (Univ. Dayton Press, Dayton, Ohio, Oct. 1968).

Brockman, J. F., Popular science writing, Proc. 1967 Inst. Technical Industrial Communications, Colorado State University, Ft. Collins, Colo., June 12-16, 1967, pp. 96-100 (1967).

Carter, G. C., The NBS Alloy Data Center, Mater. Res. Bull. 3, 919-922 (1968).

Case, W. E., Harrington, R. D., Hysteresis effects in the slope calibration method for magnetometers, Proc. IEEE 56, No. 10, 1733-1734 (Oct. 1968).

Casella, R. C., Decay modes with coherent resonant-energy transfer between deep impurities in solids, Phys. Rev. 174, No. 3, 830-834 (Oct. 15, 1968).

Casella, R. C., Time reversal and the $\mathrm{K}^{\circ}$ meson decays, Phys. Rev. Letters 21 , No. 15, 1128-1131 (Oct. 7, 1968).

Clark, A. F., Low temperature thermal expansion of some metallic alloys, Cryogenics 8, No. 5, 282-289 (Oct. 1968).

Coriell, S. R., Jackson, J. L., Bounds on transport coefficients of two-phase materials, J. Appl. Phys. 39, No. 10, 4733-4736 (Sept. 1968).

Crumlish, J. D., Notes on U.S. Government information systems, Law Computer Technol. 1, No. 11, 15-21 (Nov. 1968).

Cuthill, J. R., Dobbyn, R. C., McAlister, A. J., Williams, M. L., Search for plasmaron structure in the soft x-ray $\mathrm{L}_{2,3}$ emission spectrum of Al, Phys. Rev. 174, No. 2, 515-517 (Oct. 10, 1968).

Cuthill, J. R., McAlister, A. J., Williams, M., L., Dobbyn, R. C., Soft X-ray spectra and comparison with the theoretical density of states, (Proc. Conf. Soft X-ray Band Spectra and the Electronic Structure of Metals and Materials, Strathclyde, Scotland, Sept. 18-21, 1967), chapter in Soft X-ray Band Spectra and the Electronic Structure of Metals and Materials. Part II. Heavy Metal and Alloy Spectra and Comparison with other Optical Methods, pp. 151-162 (Academic Press Inc., New York, N.Y., 1968).

Davis, D. D., Braun, W., Intense vacuum ultraviolet atomic line sources, Appl. Opt. 7, No. 10, 2071-2074 (Oct. 1968). 
Davis, G. T., Eby, R. K., Martin, G. M., Variations of the unit-cell dimensions of polyethylene: effect of crystallization conditions, annealing, and deformation, J. Appl. Phys. 39, No. 11, 4973-4981 (Oct. 1968).

Diller, D. E., Refractive index of gaseous and liquid hydrogen, J. Chem. Phys. 49, No. 7, 3096-3105 (Oct. 1, 1968).

Douglas, T. B., King, E. G., High-temperature drop calorimetry, chapt. in Book, Experimental Thermodynamics, Ed. J. P. McCullough and D. W. Scott, Vol. I, Calorimetry of Non-reacting Systems, chapt. 8, 293-331 (Butterworth and Co., London, England, 1968).

Dragoo, A. L., Diffusion rates in solids, Chapter IV in Atomic Energy Review, O. Kubaschewski, Ed., 2, 187-202 (International Atomic Energy Agency, Vienna, Austria, 1968).

Ehrlich, M., Influence of irradiation rate on the production of F centers in LiF (TLD grade), Proc. Second Intern. Conf. Luminescence Dosimetry, Gatlinburg, Tenn., Sept. 23-26, 1968, J. A. Auzier, K. Becker, E. M. Robinson, Ed., Paper No. CONF-680920 Health and Safety (TID-4500), pp. 322-326 (Oak Ridge National Laboratory, Oak Ridge, Tennessee, Sept. 1968).

Erhlich, M., Thermoluminescence response of $\mathrm{LiF}$ to $\mathrm{X}$ - and gamma rays; a study of rate and energy dependence over a wide range of exposures, Proc. First Intern. Congress Radiation Protection, Rome, Italy, Sept. 5-10, 1966, pp. 429-434 (Pergamon Press Inc., New York, N.Y., 1968).

Ehrlich, M., Placious, R. C., Thermoluminescence response of $\mathrm{CaF}_{2}: \mathrm{Mn}$ in polytetrafluoroethylene to electrons, Health Phys. 15, 341-350 (1968).

Eisenhart, C., Zelen, M., Elements of probability, Chapter 12 in Handbook of Physics, Second ed., E. U. Condon and H. Odishaw, Editors, Part 1. Mathematics, pp. 1-163-1-197 (McGraw-Hill Book Co., New York, N.Y., 1967).

Engen, G. F., A method of calibrating coaxial noise sources in terms of a waveguide standard, IEEE Trans. Microwave Theory Tech. MTT-16, No. 9, 636-639 (Sept. 1968).

Evans, J. P., Sweger, D. M., Immersion cooler for freezing ice mantles on triple-point-of-water cells, Rev. Sci. Instr. 40, No. 2, 376-377 (Feb. 1969).

Evenson, K. M., Broida, H. P., Wells, J. S., Mahler, R. J., Mizushima, M., Electron paramagnetic resonance absorption in oxygen with the HCN laser, Phys. Rev. Letters 21 , No. 15, 1038-1040 (Oct. 7, 1968).

Fatidai, A. J., Esters of benzenepentol (pentahydroxybenzene), J. Chem. Eng. Data 14, 118-119 (1969).

Fatiadi, A. J., Nature of a colored by-product found in crude inosose phenylosazones, Carbohydrate Res. 9, 177-185 (1969).

Feldman, A., Horowitz, D., Dispersion of the piezobirefringence of GaAs, J. Appl. Phys. 39, No. 12, 5597-5599 (Nov. 1968).

Feldman, A., Horowitz, D., Stress-induced dichroism at the absorption edge of $\mathrm{SrTiO}_{3}$, Solid State Commun. 6, 607-612 (1968).

Foster, B. E., Blaine, R. L., A comparison of ISO and ASTM tests for cement strength, Am. Soc. Testing Mater. Spec. Tech. Publ. 441, 33-60 (1968).

Halford, D., Wainwright, A. E., Barnes, J. A., Flicker noise of phase in RF amplifiers and frequency multipliers: characterization, cause, and cure, Proc. 22nd Annual Symp. Frequency Control, Atlantic City, New Jersey, Apr. 22-24, 1968, pp. 340-341 (Solid State and Frequency Control Division, Electronic Components Laboratory, U.S. Army Electronics Command, Fort Monmouth, New Jersey, Apr. 1968).

Hall, J. L., The laser absolute wavelength standard problem, IEEE J. Quantum Elect. QE-4, No. 10, 638-641 (Oct. 1968).

Haller, W., Macedo, P. B., The origin of phase connectivity in microheterogeneous glasses, Phys. Chem. Glasses 9, No. 5, 153-155 (Oct. 1968).

Heinrich, K. F. J., Electron probe microanalysis: a review, Appl. Spectry. 22, No. 5, Part 1, 395-403 (Sept.-Oct. 1968).

Heinrich, K. F. J., Yakowitz, H., Quantitative electron probe microanalysis: fluorescence correction uncertainty, Mikrochim. Acta 5, 905-916 (1968).

Hicho, G. E., Meyerson, M. R., Geil, G. W., Effect of slack-quenched structures on the tensile properties of AISI 5140 steel, (Proc. Intern. Conf. Strength of Metals and Alloys), Suppl. Trans. Japan Inst. Metals 9, 134-142 (1968).

Hudson, R. P., Kaeser, R. S., Magnetic temperature scale 0.002-5 ${ }^{\circ}$ K, Proc. Xth Intern. Conf. Low Temperature Physics, Moscow, U.S.S.R., Aug. 31-Sept. 6, 1966, Vol. 1, Properties of Helium, Paper H4, 171-173 (1968).

Hummer, D. G., Non-coherent scattering. IV. Doppler redistribution functions in moving atmospheres, Monthly Notices Roy. Astron. Soc. 141, 479-488 (Dec. 1968).

Iverson, W. P., Mechanisms of microbial corrosion, (Proc. First Intern. Biodeterioration Symp., Southampton, England, Sept. 9-14, 1968), chapter in Biodeterioration of Materials. Microbiological and Allied Aspects, pp. 28-43 (Elsevier Publ. Co., Ltd., Essex, England, 1968).

Jacox, M. E., Milligan, D. E., Matrix isolation study of the vacuum-ultraviolet photolysis of trichlorosilane. The infrared spectrum of the free radical $\mathrm{SiCl}_{3}$, J. Chem. Phys. 49, No. 7, 3130-3135 (Oct. 1, 1968).

Johnson, V. J., Development and operation of a specialized technical information and data center (The Cryogenic Data Center), J. Chem. Doc. 8, No. 4, 219-224 (Nov. 1968).

Kahn, A. H., Polarons in anisotropic energy bands, Phys. Rev. 172, No. 3, 813-815 (Aug. 15, 1968).

Kim, Y-K., Inokuti, M., Chamberlain, G. E., Mielczarek, S. R., Minima of generalized oscillator strengths, Phys. Rev. Letters 21 , No. 16, 1146-1148 (Oct. 14, 1968).

Klein, M., Hanley, H. J. M., Selection of the intermolecular potential. Part 2.-From data of state and transport properties taken in pairs, Trans. Faraday Soc. 64, Part II, No. 551, 2927-2938 (Nov. 1968).

Klose, J. Z., Atomic lifetime measurements with pulsed electron beams, (Proc. Beam-Foil Spectroscopy Conf., Univ. Arizona, Tucson, Arizona, Nov. 20-22, 1967), chapt. in Book, Beam-Foil Spectroscopy, II, pp. 285-304 (Gordon and Breach Publ., New York, N.Y., 1968).

Koidan, W., Calibration of standard condenser microphones: coupler versus electrostatic actuator, J. Acoust. Soc. Am. 44, No. 5, 1451-1453 (Nov. 1968).

Laufer, A. H., McNesby, J. R., Photolysis of methane at 1236-A: quantum yield of hydrogen formation, J. Chem. Phys. 49, No. 5, 2272-2278 (Sept. 1, 1968).

Little, W. E., Patty, O. L., Zanboorie, M. H., A millimeter wave reflectometer, IEEE Trans. Microwave Theory Tech. MTT-16, No. 2, 121 (Feb. 1968).

Lloyd, E. C., Erasable trace recording methods for chart recorders, Rev. Sci. lnstr. 39, No. 12, 1953-1954 (Dec. 1968).

McCamy, C. S., A half century of photographic standardization in the United States, Photo. Sci. Engr. 12, No. 6, 308-312 (Nov.-Dec. 1968).

McIntyre, D., Mazur, J., Wims, A. M., Effects of excluded volume on light scattered from flexible macromolecules, J. Chem. Phys. 49, No. 7, 2887-2895 (Oct. 1, 1968).

Macedo, P. B., Simmons, J. H., Haller, W., Spectrum of relaxation times and fluctuation theory: ultrasonic studies on alkali-borosilicate melt, Phys. Chem. Glasses 9, No. 5, 156-164 (Oct. 1968).

Manning, J. R., Vacancy-wind effect in diffusion and deviations from thermodynamic equilibrium conditions, Can. J. Phys. 46, No. 23, 2633-2643 (1968). 
Marzetta, L. A., Noise limitations in signal detectors, Instr. Technol. 16, No. 2, 51-53 (Feb. 1969).

Mazur, J., McIntyre, D., Wims, A. M., Asymptotic behavior of the light-scattering function of coiled molecules, J. Chem. Phys. 49, No. 7, 2896-2904 (Oct. 1, 1968).

Mendlowitz, H., Calculated line strengths for the transitions between the configurations $\left(3 d^{3}+3 d^{2} 4 s\right)$ and $3 d^{2} 4 p$ in TiII, Astrophys. J. 154, pp. 1099-1110 (Dec. 1968).

Meshkov, S., Ponzini, R., Su(6) $)_{\mathrm{w}}$ and high-energy photoproduction, Phys. Rev. 175, No. 5, 2030-2034 (Nov. 25, 1968).

Meyerson, M. R., Giles, P. M., Newfeld, P. F., Dimensional stability of gage block materials, J. Mater. 3, No. 4, 727-743 (1968).

Mielenz, K. D., Gas lasers and conventional sources in interferometry, chapt. in Book, Electron Beam and Laser Beam Technology, pp. 89-137 (Academic Press Inc., New York, N.Y., 1968).

Mielenz, K. D., Length measurement and laser wavelength stability, ISA Trans. 6, No. 4, 293-297 (1967).

Mies, F. H., Configuration interaction theory. Effects of overlapping resonances, Phys. Rev. 175, No. 1, $164-175$ (Nov. 5 , 1968).

Miller, C. E., Lipsicas, M., Nuclear spin-lattice relaxation in very dilute solutions of orthohydrogen in parahydrogen, Phys. Rev. 176, No. 1, 273-279 (Dec. 5, 1968).

Milligan, D. E., Jacox, M. E., Matrix-isolation study of the vacuum-ultraviolet photolysis of dichlorosilane. The infrared spectrum of the free radical $\mathrm{SiCl}_{2}$, J. Chem. Phys. 49, No. 4, 1938-1942 (Aug. 15, 1968).

Milligan, D. E., Jacox, M. E., Matrix-isolation study of the vacuum-ultraviolet photolysis of difluorosilane. The infrared and ultraviolet spectra of the free radical $\mathrm{SiF}_{2}$, J. Chem. Phys. 49, No. 10, 4269-4275 (Nov. 15, 1968).

Milligan, D. E., Jacox, M. E., Guillory, W. A., Matrix-isolation study of the vacuum-ultraviolet photolysis of trifluorosilane. The infrared spectrum of the free radical $\mathrm{SiF}_{3}$, J. Chem. Phys. 49, No. 12, 5330-5335 (Dec. 15, 1968).

Moore, G. A., Wyman, L. L., Joseph, H. M., Comments on the possibilities of performing quantitative metallographic analyses with a digital computer, chapter 13 in Quantitative Microscopy, pp. 380-403 (McGraw-Hill, Inc., New York, N.Y., 1968).

Mozer, B., Localized modes, resonant modes and impurity vibrational bands in vanadium alloys, chapter in Neutron Inelastic Scattering, 1, pp. 55-63 (Intern. Atomic Energy Agency, Vienna, Austria, 1968).

Nemoto, T., Wait, D. F., Microwave circuit analysis using the equivalent generator concept, IEEE Trans. Microwave Theory Tech. MTT-16, No. 10, 866-873 (Oct. 1968).

Nimeroff, I., A survey of papers on degree of metamerism, Color Eng. 6, No. 6, 44-46 (Nov.-Dec. 1968).

Okabe, H., Photodissociation of $\mathrm{HN}_{3}$ in the vacuum-ultraviolet production and reactivity of electronically excited $\mathrm{NH}$, J. Chem. Phys. 49, No. 6, 2726-2733 (Sept. 15, 1968).

Powell, C. J., Characteristic energy losses of 8-keV electrons in liquid Al, Bi, In, Ga, Hg, and Au, Phys. Rev. 17̄5, No. 3, 972-982 (Nov. 15, 1968).

Powell, C. J., Interaction of electrons with solids, chapter 9.2 in Atomic and Electron Physics, Atomic Interactions, Vol. 7 , Methods of Experimental Physics, B. Bederson, Editor, Part B, pp. 275-305 (Academic Press, Inc., New York, N.Y., 1968).

Robbins, C. R., Growth of strontium titanate from a silica flux, J. Crystal Growth 2, 402-404 (1968).

Rush, J. J., Melveger, A. J., Farrar, T. C., Tsang, T., Laser-Raman spectra and hindered rotation in the phosphonium halides, Chem. Phys. Letters 2, No. 8, 621-624 (1968).

Schweitzer, W. G., Jr., Saturated absorption by neon inside a $6328 \AA$ laser with a mixture of neon isotopes in its gain tube, Appl. Phys. Letters 13, No. 11, 367-368 (Dec. 1, 1968).

Shives, T. R., Bennett, J. A., The effect of environment on the fatigue properties of selected engineering alloys, J. Mater. 3, No. 3, 695-715 (1968).

Shumaker, J. B., Jr., Franck-Condon factors for high rotational levels of nitrogen, J. Quant. Spectry. Radiative Transfer 9 , 153-156 (1969).

Smith, E. W., Hooper, C. F., Jr., Comments on ion microfield distributions as used in plasma line broadening theories, J. Quant. Spectry. Radiative Transfer 8, No. 9, 1617-1619 (Sept. 1968).

Steel, N. M., Production of synthetic food materials: A statistical survey, Proc. Second Intern. Conf. Women Engineers and Scientists, 30 pages (Women's Engr. Soc., London, England, 1968).

Stevens, M. E., Selected pattern recognition projects in Europe, Pattern Recognition 1, 103-118 (Nov. 1968).

Sugar, J., Nuclear magnetic dipole moment of ${ }^{165}$ Ho, J. Opt. Soc. Am. 58, No. 11, 1519-1523 (Nov. 1968).

Thomas, A. M., Monte Carlo study of vacuum vane gauge design criteria, J. Vacuum Sci. Technol. 5, No. 6, 187-193 (Nov.Dec. 1968).

Travis, J. C., Spijkerman, J. J., Mössbauer spectroscopy with Ni¹ , Chapter in Mössbauer Effect Methodology, 4, pp. 237-259 (Plenum Press Inc., New York, N.Y., 1968).

Tsai, D. H. Beckett, C. W., Shock wave propagation in a two-dimensional crystalline lattice (Proc. Intern. Union of Theoretical and Applied Mechanics: Intern. Symp. Behavior of Dense Media Under High Dynamic Pressure, Paris, France, Sept. 11-15, 1967), chapt. in Book, The Behavior of Dense Media Under High Dynamic Pressure, pp. 99-108(Gordon and Breach Publ., New York, N.Y., 1968).

Vieth, D. L., Yakowitz, H., Tensile loading device for Kossel microdiffraction and metallography, Rev. Sci. Instr. 39, No. 12, 1929-1931 (Dec. 1968).

Wait, D. F., Thermal noise from a passive linear multiport, IEEE Trans. Microwave Theory Tech. MTT-16, No. 9, 687-691 (Sept. 1968).

Wait, D. F., Nemoto, T., Measurement of the noise temperature of a mismatched noise source, IEEE Trans. Microwave Theory Tech. MTT-16, No. 9, 670-675 (Sept. 1968).

Weiss, B-Z., Meyerson, M. R., Localized microstructural changes and fatigue crack propagation, Trans. Met. Soc. AIME 242, 2515-2518 (1968).

Weissler, P. G., International standard reference zero for audiometers, J. Acoust. Soc. Am. 44, No. 1, $264-275$ (July 1968).

West, E. D., Westrum, E. F., Jr., Adiabatic calorimetry from 300 to $800{ }^{\circ} \mathrm{K}$, chapter 9 in Experimental Thermodynamics, Vol. I, Calorimetry of Non-reacting Systems, J. P., McCullough and D. W. Scott, Editors, pp. 333-367 (Butterworth and Co., London, England, 1968).

Westrum, E. F., Jr., Furukawa, G. T., McCullough, J. P., Adiabatic low-temperature calorimetry, chapter 5 in Experimental Thermodynamics, Vol. I, Calorimetry of Non-reacting Systems, J. P. McCullough and D. W. Scott, Edtiors, 133-214 (Butterworth and Co., London, England, 1968).

Wiese, W. L., Dependence of atomic $f$-values on nuclear charge (Proc. Conf. Beam-Foil Spectroscopy, University of Arizona, Tucson, Arizona, Nov. 20-22, 1967), chapt. in Book, Beam Foil Spectroscopy, II, 386-406 (Gordon and Breach Publ., New York, N.Y., 1968).

Wiese, W. L., Weiss, A. W., Regularities in atomic oscillator stengths, Phys. Rev. 175, No. 1, 50-65 (Nov. 5, 1968). 
Wilcox, R. M., Bounds for the isothermal, adiabatic, and isolated static susceptibility tensors, Phys. Rev. 174, No. 2, 624-629 (Oct. 10, 1968).

Williams, E. S., A voltage converter for a new era, Meas. Data 2, No. 6, 75-79 (Nov.-Dec. 1968).

Wolfe, W. C., Field study of floor coverings, Flooring 74, No. 11, 52-58 (Nov. 1968).

Wolfgang, R., Zare, R. N., Branscomb, L. M., Chemical accelerators, Science 162, 818-822 (Nov. 15, 1968).

Yakowitz, H. Heinrich, K. F. J., Inclusion identification by means of electron probe microanalysis, Metallography 1, No. 1, $55-78$ (1968).

Young, K. F., Forman, R. A., Use of polystyrene beads for manufacture of low loss coaxial lines for low temperature research, Rev: Sci. Instr. 39, No. 12, 1964-1965 (Dec. 1968).

Young, R. D., Kuyatt, C. E., Resolution determination in field emission energy analyzers, Rev. Sci. Instr. 39, No. 10, 14771480 (Oct. 1968).

*Publications for which a price is indicated are available by purchase from the Superintendent of Documents, U.S. Government Printing Office, Washington, D.C. 20402 (foreign postage, one-fourth additional). The NBS non-periodical series are also available from the Clearinghouse for Federal Scientific and Technical Information, Springfield, Va. 22151. Reprints from outside journals and the NBS Journal of Research may often be obtained directly from the authors. 